\title{
Do Institutional Investors Play Hide-and-Sell in the IPO Aftermarket? $^{1}$
}

\author{
Tamara Nefedova ${ }^{2}$ and Giuseppe Pratobevera ${ }^{3}$
}

\begin{abstract}
We document a robust buy/sell asymmetry in the choice of the broker in the IPO aftermarket: institutional investors are less likely to sell than buy through the lead underwriters. Consistent with investors hiding their sell trades, the asymmetry is the strongest in cold IPOs and it is limited exclusively to the first month after the issue. Contrary to the conventional view, the intention to flip IPO allocations is not an important motive for hiding sell trades from the lead underwriters; institutions that sell shares through non-lead brokers tend to have bought them through the lead underwriters in the IPO aftermarket, consistent with institutions breaking their laddering agreements. We find that hiding sell trades is an effective strategy to circumvent underwriters' monitoring mechanisms: the more institutions hide their sell trades, the less they are penalized in subsequent IPO allocations.
\end{abstract}

Keywords: IPO allocations, IPO aftermarket trading, laddering, flipping, institutional investors

JEL classification: G23, G24, G39

\footnotetext{
${ }^{1}$ We thank Shiu-Yik Au, Romain Boulland, François Degeorge, Michel Dubois, Laurent Frésard, Peter Gruber, Gang Hu, Chuan-Yang Hwang, Tim Jenkinson, Andy Puckett and the participants of 2018 JCF Special Issue Conference at Hong Kong PolyU, NFA 2018 in Charlevoix, 2018 SFI Research Days, and 2018 Dauphine research workshop for their insightful comments and suggestions. We thank Jay Ritter for making IPO data available on his website. All errors and omissions are our own.

${ }^{2}$ Université Paris-Dauphine and PSL Research University, CNRS, UMR[7088], DRM, 75016 Paris, France. E-mail: tamara.nefedova@dauphine.psl.eu; Acknowledgement: This research was conducted within the Research Initiative Quantitative Management Research Initiative (QMI) under the aegis of the Fondation du Risque, a joint initiative by Université Paris-Dauphine, l'ENSAE ParisTech, Addstones-GFI and La Française Investment Solutions

${ }^{3}$ Istituto di Finanza, Università della Svizzera italiana and Swiss Finance Institute, Via Giuseppe Buffi 13, 6900 Lugano, Switzerland. E-mail: giuseppe.pratobevera@usi.ch
} 


\section{Introduction}

Despite considerable research on the conflicts of interest in initial public offerings, there is little evidence describing moral hazard problems faced by IPO investors. This topic deserves attention because investors' behavior may ultimately affect the benefits and the costs of the book-building method. In particular, we are interested if the IPO mechanism in place motivates the choice of the broker(s) to which investors direct their trades in the IPO aftermarket. We hypothesize that the IPO bookbuilding method provides incentives to investors to avoid lead underwriters for their sell trades in the IPO stocks in the early aftermarket.

Institutional investors may have an incentive to hide their sell trades from the lead underwriters in the IPO aftermarket (we call it "hide-and-sell" hypothesis) for two main reasons. First, investors might try to hide their allocations sales in order to preserve their business and relationship with the lead underwriters in the IPO allocations market. A key feature of book-built IPOs is that the investment banks that underwrite the issue have considerable discretion over who receives allocations. As explained by Jenkinson and Jones (2004), one of the popular justifications for such discretion, often emphasized by investment bankers, is that underwriters can allocate shares to long-term holders of the stock in the interests of the issuer. Investors that readily sell their allocations in the IPO aftermarket, commonly referred to as "flippers", tend to put a downward pressure on the trading price. While this might not be a relevant concern in hot IPOs, where flipping may serve to increase market liquidity, the selling pressure generated by flippers could lower the price below the offer price in cold offerings (see Aggarwal (2003)). Underwriters may find it convenient to reward institutions that play a supportive role and do not flip their allocations, as they play a role as market makers in the secondary market (Ellis et al. (2000)), and they may face reputational losses in case of poor 
aftermarket performance and too much flipping activity (Aggarwal (2003)). Consistent with this view, Chemmanur et al. (2010) find that investors receive larger allocations when they hold their allocations for longer periods. This gives investors an incentive to hide their allocation sales from the lead underwriters. We label this incentive as the "allocation sales explanation". Some existing studies suggest that investors may try to hide their allocation sales in post-IPO trading (Griffin et al. (2007), Chemmanur et al. $(2010))$.

The second reason for hiding sell trades from the lead underwriters is related to the practice known as "laddering", which involves a quid-pro-quo arrangement between underwriters and their clients: investors receive IPO allocations in exchange for a commitment to purchase additional shares in the aftermarket. The clients that enter such an agreement are called "ladderers". As explained by Hao (2007) and Griffin et al. (2007), laddering could be beneficial for the lead underwriters as the buying pressure from ladderers could reduce the underwriters' price support costs in the IPO aftermarket, especially in cold IPOs. Moreover, the pre-arranged client demand in the aftermarket may increase underwriters' brokerage commission revenues. The Securities and Exchange Commission (SEC) considers laddering as a manipulative practice prohibited by Rule 101 of Regulation M under the Securities Exchange Act of 1934. However, the legal definition of laddering requires the aftermarket purchase to be a condition imposed by the underwriter, thus leaving some space for implicit quid-pro-quo arrangements in which investors volunteers to buy additional shares (Hao (2007)). Consistent with lead underwriters engaging in laddering agreements with their clients, Griffin et al. (2007) find that investors are net buyers through the lead underwriters in a sample of Nasdaq IPOs. We posit that ladderers may have an incentive to break their quid-pro-quo arrangements if the shares that they committed to buy in the secondary market are in excess of their optimal holdings in the IPO firm. The potential costs for the investors 
that break the agreement, in terms of future business with the underwriters, may incentivize them to hide their sell trades. We label the incentive to hide sell trades that break investors' laddering agreements with the lead underwriters as "laddering explanation". To the best of our knowledge, we are the first to document that laddering mechanism may provide an incentive for the investor to avoid the underwriting brokers when selling the IPO stock in the aftermarket.

The hiding strategy that we consider in this paper is to sell IPO shares through brokers other than the lead underwriters (henceforth, "non-lead brokers"). We motivate our focus on this hiding strategy because of its simplicity of execution, as institutional investors usually trade through more than one brokerage house (Goldstein et al. (2009)). If the hide-and-sell hypothesis holds, and investors use this simple hiding strategy, then we should observe them to be less likely to trade through the lead underwriters when they sell, than when they purchase shares in the IPO aftermarket. We directly test this prediction using detailed institutional trading data, which allow us to control for important variables that may affect both the selling decision and choice of the broker, such as the relationship between the institution and the lead underwriters or any other institution-IPO specific characteristic. To the best of our knowledge, we are the first to directly test this prediction. Our analyses document a robust buy/sell asymmetry in the choice of the broker in the IPO aftermarket: institutional investors are significantly less likely to sell than buy through the lead underwriters during the first month of trading after the IPO.

We consider two factors that may affect the hiding incentives of financial institutions. First, if the buy/sell asymmetry is driven by hiding incentives, then it should be the strongest in cold IPOs: both the "allocation sales explanation" and the "laddering explanation" predict the lead underwriters to be concerned the most about investors' selling activity in weak offerings. Second, if the buy/sell asymmetry is driven by hiding 
incentives, then we should not be able to detect it when there are no incentives to hide stock sales from the lead underwriters. We perform placebo tests to show that the buy/sell asymmetry disappears after few months from the issue date and in a matched sample of non-IPO stocks. Overall, our evidence is consistent with the predictions of the hide-and-sell hypothesis.

The buy/sell asymmetry may be driven by both the "allocation sales explanation" and the novel "laddering explanation". Our data and methodology allow us to disentangle allocation sales from investors' buying and selling activity in the secondary market. Hence, we can investigate the reasons behind institutions' hiding behavior, in order to understand whether it is driven by flipping or laddering motives.

We argue that the "allocation sales explanation" might be overall weak in the United States because underwriters receive reports documenting the allocation sales of their customers. Flipping of shares is tracked via the Depository Trust Company's (DTC) IPO Tracking System and the lead underwriters receive two types of reports (Aggarwal (2003)). The first report provides them with client-level information about flipping activity of the investors to whom they allocated IPO shares. The second report provides them with information about the aggregate flipping activity for each syndicate member, but this does not include client-level details. Therefore, lead underwriters can detect their clients who sold their allocations, but do not have direct access to the identity of flippers that received their allocations from other syndicate members. Consequently, investors that received IPO shares from other syndicate members have some chances to hide their flipping activity from the lead underwriters by avoiding selling through them. Morevover, flipping reports are not flawless and there is anecdotal evidence of institutional investors circumventing the DTC IPO Tracking System. ${ }^{4}$ Though imper-

\footnotetext{
${ }^{4}$ Griffin et al. (2007) report that "in March 2005, the NASD fined Spear, Leeds and Kellogg with $\$ 1$ million for concealing IPO shares from the DTC system from August 1997 to January 2001".
} 
fect, the DTC IPO Tracking System dampens the scope for hiding flipping trades. The risk of being caught by the lead underwriters might not be zero even for other syndicate members' clients, as lead underwriters could exploit their relationship with the other syndicate members or use allocations and aggregate flipping data to infer flippers' identities. Since a great portion of the IPO shares are underwritten by the lead managers (Corwin and Schultz (2005)), the incentive to hide allocations sales might be overall weak.

On the contrary, the hiding behavior that we investigate in this paper, that is, selling IPO shares through non-lead brokers, might allow investors to break their laddering agreements without being caught by the lead underwriters. Ladderers may purchase the shares that they committed to buy through the lead underwriters and then sell the shares in excess of their optimal holdings through any other broker. Since these stock sales (henceforth, "other sales" or "other sell trades" or "secondary sales") do not involve allocation sales, they are not detected by the DTC IPO Tracking System and leave scope for hiding them.

We disentangle allocation sales from other sales and, consistent with the above arguments and contrary to the conventional view, we find that flipping is not a relevant motive for the institutions to hide their sell trades: the buy/sell asymmetry is mainly driven by sell trades other than allocation sales. Furthermore, we investigate other predictions of the novel laddering explanation. First, if investors break their laddering agreements, then it has to be the case that they sell the shares that they committed to buy through the lead underwriters. Second, if investors hide the breaking of the agreement and use the simple hiding technology considered in this paper, then they should tend to execute a higher proportion of their sell trades through non-lead brokers when they buy shares through the lead underwriters and when they sell secondary shares. Third, investors that buy through the lead underwriters in the aftermarket and 
want to hide their secondary sales, should avoid allocation sales. Because of flipping reports, allocation sales signal to the underwriters that an investor sold more shares than it bought in the aftermarket, meaning that it sold also secondary shares. These three arguments predict a positive correlation between the proportion of sell trades executed through non-lead brokers, the volume of shares bought through the lead underwriters, and the volume of other sales, and a negative correlation between the volume of shares bought through the lead underwriters and the volume of shares flipped. Overall, we find evidence consistent with these predictions and with financial institutions breaking their laddering agreements.

Finally, we find that hiding sell trades is an effective strategy to circumvent underwriters' monitoring mechanisms: the more institutions hide their sell trades, the less they are penalized in subsequent IPO allocations.

The idea that investors may hide their sell trades is not new. However, the literature has exclusively framed it within the allocation sales explanation. Some existing studies suggest that investors might try to hide their allocation sales from the lead underwriters in the IPO aftermarket. For example, Griffin et al. (2007) find that investors are overall net sellers through brokers that do not belong to the syndicate group and net buyers through the lead underwriters during the first month after the issue. Using institutional trading data, Chemmanur et al. (2010) finds that institutional investors abnormally split their orders in the IPO aftermarket and suggest that it might be an attempt to hide flipping trades. In both papers, the idea is that flippers would like to hide their allocations sales in order to preserve their business with the lead underwriters in subsequent IPOs.

Though suggestive and relevant, the existing evidence is far from being conclusive. Investors could split their orders or sell through non-lead brokers for reasons other than hiding. For example, they could split their trades in order to generate a stream of 
abnormal commissions to the lead underwriters as a reward for receiving IPO allocations (Reuter (2006), Nimalendran et al. (2007), Goldstein et al. (2011), and Jenkinson et al. (2017)). The difference in net buy between lead underwriters' clients and non-lead brokers' clients might be driven by the characteristics of the trading institutions, such as their relationship with the lead underwriters. Since institutional investors tend to keep stable relationships with their brokers (Goldstein et al. (2009)), some of them being connected to underwriting brokers through common educational background (Hwang et al. (2018)), institutions that are usual underwriters' clients are more likely to trade with them in the IPO aftermarket. In order to preserve this relationship, they may also be more likely to support IPO prices by buying or avoiding to sell in the secondary market. On the contrary, institutions that are not usual underwriters' clients are more likely to trade with their own usual brokers in the IPO aftermarket and may also be more likely to sell IPO stocks. Moreover, the existence of flipping reports dampens the scope for hiding allocations sales through any trading strategy in the aftermarket. The questions whether, to what extent, and why institutions may hide their trades remained open. The aim of this paper is to shed light on them.

Our findings contribute two streams of research. First, our paper is related to an extensive literature that investigates the benefits and costs of the bookbuilding method of bringing companies public. While underwriters' discretion may have the benefits of incentivizing investors' information production (Benveniste and Spindt (1989), Benveniste and Wilhelm (1990), Sherman (2000), Cornelli and Goldreich (2001), and Sherman and Titman (2002)) and of placing allocations in the hands of long-term investors (Aggarwal (2003), Jenkinson and Jones (2004), Jenkinson and Jones (2009), and Chemmanur et al. (2010)), an increasing body of research unravels the conflicts of interest inherent to the bookbuilding method (Loughran and Ritter (2004), Reuter (2006), Griffin et al. (2007), Hao (2007), Nimalendran et al. (2007), Ritter and Zhang (2007), Jenkinson and 
Jones (2009), Liu and Ritter (2010), Goldstein et al. (2011), Ritter (2011), Jenkinson et al. (2017), and Hwang et al. (2018)). ${ }^{5}$ As the existing literature mainly focuses on the conflicts of interest between underwriters and issuers, we enrich it by investigating a so far overlooked moral hazard problem faced by investors. Our findings suggest that investors' hiding behavior may affect the potential benefits and costs of underwriters' discretion and stimulate further research to study the incentives of IPO investors.

Second, we shed light on the determinants of the choice of the broker by financial institutions. Our findings are consistent with models in which investors face a tradeoff between preserving long-term relationships with brokers that give them access to premium services and the need to hide their trading strategies (Goldstein et al. (2009)). We find a clear persistence in the choice of the broker, which cannot be explained trading costs and depends strongly on the long-term relationship between institutions and their brokers. We show how hiding incentives affect the choice of the broker in the context of IPOs.

The rest of the paper is organized as follows. Section 2 describes our sample selection criteria, defines the main variables used in our analyses, and provides summary statistics. Section 3 presents our baseline results and documents that institutions are less likely to trade through the lead underwriters when they sell than when they buy shares in the IPO aftermarket, especially in cold IPOs, consistent with our hide-andsell hypothesis. This section includes placebo analyses to check that this behavior is not present when there are no hiding incentives. Section 4 investigates the motivations of institutional hiding behavior. Section 5 rules out potential alternative explanations and addresses endogeneity problems.Section 6 investigates the effectiveness of the hiding behavior in an attempt of the institutions to preserve their relationship with the

\footnotetext{
${ }^{5}$ See Lowry et al. (2017) for a recent comprehensive survey of the IPO literature.
} 
underwriter. Finally, Section 7 concludes.

\section{Data and summary statistics}

\subsection{IPO data}

We use the Thomson Financial Security Data Company (SDC) database to identify IPOs made in the United States from 1999 to $2010 .{ }^{6}$ We exclude all American Depository Receipts (ADRs), Real Estate Investment Trusts (REITs), unit and rights offerings, closed-end funds, IPOs with SIC codes between 6000 and 6199 and IPOs with offer price smaller than $\$ 5$. We further require IPOs to have a match with the Center for Research in Security Prices database (CRSP) within seven calendar days from the issue. These filters leave us with 1,439 IPOs. In addition, we require IPOs to have a CUSIP match with the ANcerno/Abel Noser Solutions database, which provides us with detailed institutional trading data. We describe ANcerno trading data in the next subsection. This criterion leads us to drop 51 IPOs. We drop three IPO firms that show inconsistent data: these firms show trading activity in the ANcerno database before the IPO date. Finally, we require at least one lead underwriter of each IPO to be matched with a broker of the Abel Noser Solutions database. This filter leaves out 24 firms. Our final sample consists of 1,361 IPOs involving 89 distinct lead underwriters. The number of IPOs varies considerably by year, ranging from 14 in 2008 to 373 in 1999 .

By matching SDC and CRSP, we get the percentage return from the IPO offer price to the first day closing price (Underpricing) and we winsorize it at the $95 \%$ level. The average underpricing in our sample is $37.6 \%$ and the median is $14.8 \%$. Since our hideand-sell hypothesis depends on underpricing, we split our sample into terciles based on this variable. We define an IPO as "hot" if it is in the highest tercile (Underpricing >

\footnotetext{
${ }^{6}$ We apply corrections to our sample of IPOs using the information provided by Jay R. Ritter at the University of Florida as of April 2014: https://site.warrington.ufl.edu/ritter/ipo-data/.
} 
$29.4 \%)$, "weak" if it is in the middle tercile $(5.1 \%>$ Underpricing $\leq 29.4 \%)$, and "cold" if it is in the lowest tercile (Underpricing $\leq 5.1 \%$ ).

\subsection{Institutional trading data in the IPO aftermarket}

We obtain institutional trading data for our sample of 1,361 IPOs from the ANcerno/Abel Noser Solutions database. The IPO trading data covers the period from January 1999 to March 2011. For each trade placed by an institution, we get the following information: the name and the identity code ("managercode") of the institution, the name and the identity code ("brokercode") of the broker executing the trade, the trading date, the CUSIP of the stock traded, the number of shares traded, a variable identifying the side of the trade (buy or sell), the execution price, and the commissions paid. The reader may refer to the Appendix A for the detailed description of the database.

We require trades to have non-missing managercodes and brokercodes, and to be sent to ANcerno by pension plan sponsors or money managers. ${ }^{7}$ We match the Abel Noser Solutions database to the Thomson Reuters Institutional 13F Holdings database by institution names. We require institutions to have a match with $13 \mathrm{~F}$. A description of the matching procedure across several databases is provided in Figure A1 of the Appendix A.

Summary statistics for more than 1.2 million institutional trades during the first year after the issue date are presented in Table 1.8 The trades in the sample are placed by 227 distinct institutions of Abel Noser Solutions and are executed by 700 different brokers. The average trade involves 6565 shares. 8.2 billion IPO shares are traded during the

\footnotetext{
${ }^{7}$ This means that we require trades to have client-type code equal to 1 or 2 . We exclude the relatively small amount of trades sent to ANcerno by brokers.

${ }^{8}$ Results are similar if we exclude IPOs issued after March 2010, thus ensuring we have full 12 months of trading data for all IPOs in our sample
} 
first year from the issue, for a total value of 251.9 billion US dollars. Lead underwriters have a large weight in the brokerage market of IPO stocks: during the first month after the IPO date, $40.4 \%$ of the IPO shares are traded through the lead underwriters. The percentage decreases in subsequent months to about 15\%. The market share of brokers that did not participate in the underwriting syndicate (henceforth, "other brokers") shows the opposite pattern: it is $52.4 \%$ during the first month after the IPO date and it increases in subsequent months to about $70 \%$.

Our hide-and-sell hypothesis predicts that institutional decision to trade with the lead underwriters depends on the side of their trade. Figure 1 breaks down the market share of the lead underwriters for buy trades (black lines) and sell trades (light grey lines). For each IPO, we compute the percentage volume of institutional buy and sell trades executed by the lead underwriters and other brokers in each month from the IPO date. Then we average these percentages across IPOs and compute $95 \%$ confidence intervals around the means. Panel (A) shows that the weight of the lead underwriters during the first month after the IPO date differs significantly depending on the trade side: it is almost $40 \%$ for buy trades and it is below $30 \%$ for sell trades, consistent with hiding behavior. 9 The market share of buy and sell trades becomes insignificant after the first month, consistent with hiding incentives being at place only during the first month of trading. Panels (B)-(D) break down the brokerage market share by underpricing terciles. We notice that the difference between buy and sell trades is mainly driven by cold IPOs, consistent with the intuition that hiding incentives are stronger in cold IPOs.

In the rest of the paper, we aggregate Abel Noser Solutions' trade volumes at the

\footnotetext{
${ }^{9}$ These numbers are slightly different from those in Table 1 because Figure 1 computes the average broker market shares in IPOs, while Table 1 computes brokerage market shares in the IPO aftermarket for IPOs as a whole.
} 
daily level. Thus, our trading dataset comprises observations at the IPO-institutionbroker-day level. Henceforth, with the word "trade" we mean "daily trade". The daily level of aggregation allows us to neglet intra-day trading decisions, which might involve several factors unrelated to our subject of study, such as institutions' churning shares to generate commissions to the lead underwriters (Goldstein et al. (2011)). Morevover, it allows us to avoid complications related to the intra-day trading time reported by the Abel Noser Solutions database. Figure 2 focuses on the first 21 trading days after the IPO. For each IPO, we compute the total amount bought and sold in each day by institutions that trade through the lead underwriters, through other syndicate members, and through brokers that did not participate in the IPO syndicate (bars). We also compute the cumulative netbuy of lead managers' clients, syndicate members' clients, and other brokers' clients (lines). The volume traded is scaled by the number of shares issued and it is averaged across IPOs. Panel (A) plots buy, sell, and cumulative netbuy volumes for all sample IPOs. Broadly consistent with the existing literature (see Griffin et al. (2007), we observe that institutions are net buyers through lead managers and syndicate members and net sellers through other brokers in the first few trading days after the IPO. Moreover, the daily volume sold tends to be larger through other brokers than through the lead underwriters; on the contrary, the daily volume bought tends to be larger through the lead underwriters than through other brokers. Finally, the difference in net buy between lead underwriters' clients and other brokers' clients is greater in cold IPOs. This is broadly consistent with hiding behavior.

The graphical evidence presented in this section suggests that some hiding behavior might be at place, but it is far from being conclusive. For example, the difference between buy and sell trades might be driven by institutional characteristics affecting both the decision to sell and the decision to trade with the lead underwriters, without any them having an intention to hide their trades. Institutions that decide to buy IPO 
shares and support the price of cold IPOs might be usual lead underwriters' clients; therefore, they might also tend to trade more through lead underwriters in the IPO aftermarket. Institutions that decide to sell IPO shares migth not be usual lead underwriters' clients; therefore, they might also tend to trade more through their usual brokers in the IPO aftermarket. Our institution-level analysis in section 3 sheds light on these issues and directly tests the predictions of the hide-and-sell hypothesis.

\subsection{Identifying institutional IPO allocations sales}

We identify institutional IPO allocations sales following the algorithm proposed by Chemmanur et al. (2010), which is consistent with the Depository Trust Company's (DTC) IPO Tracking System. The objective is to disentangle an institutional allocations sales from its buying and selling activity in the IPO aftermarket. In order to do so, we classify as IPO allocation sales only shares sold in excess of the shares bought until a specific point in time by an institution. For example, consider an institution that buys 500 shares in the secondary market during the first day after the issue date and then sells 300 shares on the second day and 300 shares on the third day. Then the IPO allocation sales of that institution are equal to zero on day 1 and 2 and are equal to 100 on day 3 .

Our sample institutions flip $3.2 \%$ of the shares offered within the first 21 trading days post-IPO and continue to sell their allocations in subsequent months. By the end of the first year, our sample institutions flip $8.5 \%$ of the shares issued on average. The amount of flipping is the highest for hot IPOs (almost $12 \%$ at the end of the first year) and the lowest for cold IPOs (less than $5 \%$ at the end of the first year). For more details on flipping activity of our sample institutions refer to figure B2 of the Appendix. 


\subsection{Identifying institutional IPO allocations}

We identify IPO allocations by combining institutional trading data with quarterly holdings data reported in $13 \mathrm{~F}$. The basic idea is to compute IPO allocations as the difference between the institutional holdings in the IPO firm at the first 13F filing date following the IPO and the net buying by the institution in the IPO firm between the IPO date and the $13 \mathrm{~F}$ filing date. However, as pointed out by Chemmanur et al. (2010), it is unlikely to compute allocations precisely by matching $13 \mathrm{~F}$ and the Abel Noser's Solution Database because of data differences in the two databases. For example, 13F might not contain all stock holdings, as institutions are required to disclose common stock positions greater than 10,000 shares or $\$ 200,000$. This kind of matching problems might generate some inconsistencies when computing allocations as holdings minus net buying. For example, we might compute negative allocations and/or allocations smaller than the amount of shares flipped.

In order to rule out these inconsistencies, we complement our allocation proxy with allocation sale data. The idea is that an IPO allocation has to be at least equal to the amount of shares flipped by the institution. Formally, we proxy IPO allocations as follows. We denote $H_{i, j}$ as the number of shares of IPO $i$ held by institution $j$ at the first filing date after the IPO; $\Delta_{i, j}$ as the total netbuy of IPO $i$ shares by institution $j$ between the IPO date and the first filing date after the IPO; and Let $F_{i, j}$ as the number of shares of IPO $i$ flipped by institution $j$ - as computed in section 2.3 - in the first three months after the IPO. We then compute the percentage of shares of IPO $i$ allocated to institution $j$, AllocPerc $_{i, j}$, as:

$$
\text { AllocPerc }_{i, j}=\frac{\max \left(H_{i, j}-\Delta_{i, j}, F_{i, j}\right)}{\text { SharesIssued }_{i}} 100
$$

and we winsorize it at the $95 \%$ level. Table 2 reports IPO allocations summary statistics at the institution and issuer level. Conditional on receiving an allocation, 
an average institution gets $1.89 \%$ of the issue. In an average IPO, about 23 sample institutions receive an allocation and get $42.7 \%$ of the offer.

Allocations vary with underpricing. Institutions that receive cold IPO shares get a larger percentage of the issue than institutions that receive hot IPO shares $(2.53 \%$ versus $1.53 \%$ ). However, the number of institutions that receive allocations is much smaller in cold IPOs than in hot IPOs (13.6 versus 30.6). Thus, the total allocation to institutional investors is lower in cold IPOs than in hot IPOs (34.3\% versus 47\%).

\section{Do institutional investors hide their sell trades?}

\subsection{Main specifications}

If investors systematically hide some of their sell trades from the lead underwriters (hide-and-sell hypothesis) by trading with other brokers, then we should observe the probability of trading through the lead underwriters to be lower for sell trades than for buy trades in the IPO aftermarket. In order to test this prediction, we run several specifications of the following linear probability model $(\mathrm{LPM})^{10}$ :

$$
\operatorname{LeadDummy}_{i, j, b, t}=\alpha+\beta \operatorname{Sell}_{i, j, b, t}+X_{i, j, b, t} \Gamma+\delta_{j}+\theta_{i}+\lambda_{i, j}+u_{i, j, b, t}
$$

where $S e l l_{i, j, b, t}$ is a dummy variable equal to one if the institution $j$ is selling the IPO $i$ through broker $b$ on day $t$ and zero if it is buying. The dependent variable, LeadDummy $y_{i, j, b, t}$, is a dummy variable equal to one if the broker $b$ executing the trade is any of the lead underwriters of IPO $i$ and zero otherwise. $X_{i, j, b, t}$ is a vector of

\footnotetext{
${ }^{10}$ We choose the linear probability model because it allows us to control for fixed effects without incurring in the incidental parameter problem and to estimate marginal effects. The potential bias and inconsistency of OLS with binary outcome are unlikely to be a concern in our setting, as the average value of the dependent variable is not at the boundaries of the unit interval (it is 0.292). For monitoring purposes, we keep track of the proportion of predicted probabilities outside the $[0,1]$ interval in our regression tables.
} 
control variables, which are described below; $\delta_{j}, \theta_{i}$, and $\lambda_{i, j}$ are institution, IPO, and institution-IPO fixed effects; $u_{i, j, b, t}$ is the error term, which we allow to be correlated within institution. The hide-and-sell hypothesis predicts $\beta<0$.

The vector of control variables includes the trading volume RelVol, which is the number of shares traded by the institution scaled by the number of shares issued and multiplied by 100 . We control for the relationship between institutional investors and lead underwriters. Lead underwriters' usual clients are more likely to choose a lead underwriter as a broker at any point in time, including the IPO aftermarket (see Goldstein et al. (2009)). They might also be more likely to support the IPO price to preserve their relationship with the underwriters, thus being less likely to sell IPO shares than other investors. Conversely, institutions that are not usual underwriters' clients are less likely to trade with them and might be more likely to be IPO sellers. Therefore, a negative correlation between the decision to sell IPO shares and the decision to trade with a lead underwriter might be driven by the relationship between investors and underwriters. We control for it by means of the variable NormalTradeLead. For each institution-IPO pair, we compute the percentage volume traded in non-IPO stocks by the institution through the lead underwriters in a 6 -month period prior to the issue. ${ }^{11}$ We compute this variable separately for buy and sell trades, to capture any potential heterogeneity in the investor-lead underwriters relationship by trade side. We include in the specification the variable Day, which is the day in which the trade is executed relative to the issue date, in order to control for the likely decreasing trend in the probability of trading with a lead underwriter. One important determinant of the choice to trade with the lead underwriters might be their trading expenses. ExcLeadComm is the average percentage commission to the lead underwriters minus the average percentage commission to any

\footnotetext{
${ }^{11}$ The 6-month period includes trades in non-IPO stocks executed from the trading day -147 to the trading day -22 before the issue date.
} 
other broker paid by sample institutions in the first 21 trading days after the issue date. With this variable we capture how expensive it is to trade with the lead underwriters relative to other brokers in the IPO aftermarket. We compute this variable separately for buy and sell trades to capture any potential heterogeneity in brokerage commissions by trade side. Finally, we control for the percentage IPO allocation received by an institution, AllocPerc. Institutions that receive IPO allocations might be more likely to trade with the underwriters for several reasons, including quid-pro-quo agreements to generate a stream brokerage commissions to the lead underwriters (Goldstein et al. (2011), Reuter (2006), and Nimalendran et al. (2007)) and "laddering" agreements to buy shares in the IPO aftermarket (Griffin et al. (2007)).

Table 3 reports the OLS estimation results. We use standard errors clustered at the institution level for inference. ${ }^{12}$ Panel (A) includes trades executed during the first 21 trading days after the issue date. We focus on this period because lead underwriters' practices suggest that investors' incentives to hide their sell trades should exist mainly during the first month of trading. Lead underwriters track IPO flipping through the Depository Trust Company's (DTC) IPO Tracking System and engage in market stabilization activities usually during the first 30 calendar days after the issue date (see Aggarwal (2000)). In Column (1) we regress LeadDummy on Sell; column (2) introduces control variables in the specification; columns (3), (4), and (5) control for institution, institution and firm, and institution-firm fixed effects.

The coefficient of the variable Sell is negative and statistically significant in all specifications. Considering the estimate in column (1), institutional investors are 6 percentage points less likely to trade through a lead underwriter when they sell IPO shares than when they buy, consistent with the hide-and-sell hypothesis. The coefficient

\footnotetext{
${ }^{12}$ In unreported analyses, we allow the error term to be correlated within IPO, clustering standard errors at the firm level. The results become stronger.
} 
is statistically significant at least at the $5 \%$ level. It is also economically significant: the probability of selling with a lead underwriter is almost $20 \%$ less than the probability of buying $(0.06 / 0.32)$. The correlation survives when we control for institution, firm, and institution-firm fixed effects. Column (3) controls for institution fixed effects, such as their usual trading strategies in IPOs. Column (4) introduces IPO fixed effects, which capture any IPO-specific characteristics, including the identity of the lead underwriters. It might be argued that NormalTradeLead controls only for the past relationship between institutions and lead underwriters in brokarage services, but not for their future expected relationship nor for their relationship in other services; in column (5) we control for any institution-IPO specific factor, exploiting within institution-IPO variation: an institution that is both buying and selling a given IPO is more likely to trade with the lead underwriters when it buys than when it sells.

The coefficient of RelVol is positive and significant in all specifications: institutions that make larger trades are more likely to trade with the lead underwriters. A one percentage point increase in the trading volume is associated with about 13 percentage points increase in the probability of trading with a lead underwriter. As expected, there is a positive and statistically significant correlation between LeadDummy and NormalTradeLead. A one percentage point increase in the proportion of trades that the institution normally execute through the lead underwriters is associated with about 0.9 percentage points increase in the probability of trading with a lead underwriter in the IPO aftermarket. The coefficient becomes much smaller and statistically insignificant when we control for institution-firm fixed effects, suggesting that the relationship between investors and underwriters is homogeneuos across trade side and, thus, captured by these fixed effects. As expected, the coefficient of Day is negative and statistically significant. A one day increase in the trading time relative to the issue date is associated with about one percentage point decrease in the probability of trading with a 
lead underwriter. The coefficient of ExcLeadComm is negative in all specifications. However, it is statistically significant only when we control for institution-firm fixed effect. Even though commissions does not seeem to be a main driver of the choice of the broker, differences in trading commissions across trade side help explain the within institution-IPO variation of LeadDummy. Finally, AllocPerc is only weakly significant in one specification (at the 10\% level). Moreover, its sign flips across specifications. We cannot make definitive conclusions about its correlation with the choice of the broker in the IPO aftermarket.

In unreported results we replicate our analysis considering trades executed during the first 7 trading days after the issue date. The coefficient on Sell gets much stronger in all specifications, suggesting that most of the documented effect is concentrated in the first few trading days after the IPO.

\subsection{Hiding incentives in cold IPOs}

Hiding incentives are stronger in cold IPOs. Underwriters are more likely concerned by sell trades when the aftermarket demand for the IPO stock is weak, because sell trades put additional downward pressure on the price (Chemmanur et al. (2010)). Hence, we hypothesize the buy/sell asymmetry in the choice of the broker to be stronger in cold IPOs. We define the variable ColdIPO $O_{i}$ to be equal to one if the firm $i$ is in the lowest tercile of the variable Underpricing Und $_{i}$ and zero otherwise. We introduce an interaction variable between $\operatorname{ColdIPO}_{i}$ and $\operatorname{Sell}_{i, j, b, t}$ in our regression specifications. Under the hide-and-sell hypothesis, we expect the coefficient on the interaction term to be negative. We report the estimation results in Column (6) of Table 3.

Consistent with the hide-and-sell hypothesis, the negative correlation between LeadDummy and Sell is stronger when hiding incentives are more pronounced. The coefficient of the interaction term is negative and statistically significant at least at the $5 \%$ level. The 
economic magnitude is also significant: investors are about 10.5 percentage points less likely to trade with a lead underwriter when they sell shares of cold IPOs than when they buy shares in cold IPOs.

\subsection{Placebo tests}

If institutional investors are less likely to sell through the lead underwriters because they try to hide their sell trades, then we should not observe this behavior when there is no incentive to hide.

Lead underwriters' practices suggest that investors' incentives to hide their sell trades should exist mainly during the first month of trading. Hence, we should not detect systematic hiding behavior after the first month. Column (7) of Table 3 implements our regression analysis for institutional investors' trading activity during the third month after the IPO date. The coefficient of Sell is not statistically different from zero and its magnitude is very small.

The hiding incentive is peculiar to IPOs: it should not exist for non-IPO stocks. Hence, we test the hide-and-sell hypothesis in a matched sample of trades in non-IPO stocks. We match trades as follows. First, we require candidate non-IPO stocks to be similar to the matched IPO. For each IPO, we select candidate non-IPO stocks that: (i) are in the same one-digit industry; (ii) are in the same quintile of market capitalization; (iii) are in the same tercile of Tobin's Q. ${ }^{13}$ Then, we match each buy (sell) trade in IPO stocks with a buy (sell) trade made by the same institution in a candidate non-IPO stock within a 21 trading days window from the IPO date. The matched trade is the one with the closest dollar volume. We lose 1,909 trades in 55 IPOs because of missing data about market capitalization, industry, or Tobin's Q. Moreover, we lose 13,677 trades because of no match found. Our final sample consists of 28,990 trades in non-

\footnotetext{
${ }^{13}$ We get this data from CRSP and COMPUSTAT.
} 
IPO stocks matched to 1,109 IPOs. ${ }^{14}$ Column 8 of Table 3 implements our regression analysis for institutions' trading activity in non-IPO stocks. The coefficient of Sell is not statistically different from zero and economically small.

Overall, our placebo tests confirm that the buy/sell asymmetry in the choice of the broker is peculiar to the IPO aftermarket, consistent with hiding incentives.

\section{Why do institutional investors hide their trades?}

In this section, we investigate the drivers and motives of institutional investors' hiding behavior. The existing literature suggests that investors might try to hide their allocations sales in order to preserve their business with the lead underwriters in the IPO allocations market (Griffin et al. (2007), Chemmanur et al. (2010)). Though relevant, consistent, and sound, the incentive to hide allocation sales might be overall weak because of the lead underwriters' ability to infer flippers' identities: though imperfect, the flipping reports produced via the DTC IPO Tracking System dampen unambiguously the investors' chances to hide their allocation sales. We find evidence consistent with this view by introducing in our baseline regression 4 the dummy variable AllocationSaleDummy that takes the value of one when the sell trade contains an allocation sale and zero otherwise. ${ }^{15}$ AllocationSaleDummy trades are a subset of Sell trades, thus every AllocationSaleDummy is a Sell, but not vice versa. For the sake of the interpretation of the regression coefficients, AllocationSaleDummy is essentially

\footnotetext{
${ }^{14}$ The median volume difference between matched non-IPO trades and original IPO trades is 50 dollars. The correlation between dollar volumes of original and matched trades is 0.7 .

${ }^{15}$ Since we observe allocation sales at the institution-IPO-day level (see section 2.3 ), this definition of AllocationSaleDummy may be inaccurate if investor $j$ executes both secondary sales and allocation sales of IPO $i$ during the same trading day $t$ through several distinct brokers $b$. In our sample, this problem can affect at most 645 observations out of 44,576. In Table 4, we assume that all of these 645 sell trades contain an allocation sale. In unreported analyses, we exclude these 645 observations from the sample and find similar results.
} 
an interaction variable because it can take the value of one only when Sell is also one. ${ }^{16}$

Table 4 shows that the buy/sell asymmetry is mainly driven by sell trades other than allocation sales (we refer to these sales as secondary sales throughout the paper. The coefficient of AllocationSaleDummy is positive and significant, meaning that sell trades are significantly more likely to be executed through the lead underwriters when they contain allocation sales, than when they do not contain allocation sales. Nevertheless, there is evidence of some hiding activity also for allocation sales: sell trades that contain allocations sales are somewhat less likely to be executed through the lead underwriters than buy trades, as the coefficient of Sell plus the coefficient of AllocationSaleDummy is a negative number.

We suggest a novel reason for why investors might have an incentive to hide their sell trades. An investor that enters in a laddering agreement a là Hao (2007) receives an IPO allocation and agrees with the lead underwriters to generate additional demand in the IPO aftermarket by buying shares. As argued by Griffin et al. (2007), this form of laddering helps explaining why investors are overall net buyers through lead underwriters in the IPO aftermarket. However, investors might have an incentive to break the laddering agreement if the shares bought in the secondary market are in excess of their optimal holding in the IPO firm. A way to do it without being caught by the lead underwriters is to sell the shares in excess through any other broker. If investors systematically break their laddering agreements, then we should observe them simultaneously buying through the lead underwriters and selling through non-lead brokers. Column (5) of Table 3 is consistent with this view: since we control for institution-firm fixed effects, we do observe institutional investors that simultaneously buy and sell an

\footnotetext{
${ }^{16}$ This may raise a concern of collinearity between AllocationSaleDummy and Sell. Standard regression diagnostic suggests that this is not the case. In unreported results, we modify our regression specification by subtracting allocation sales from the sell transactions. Our results are consistent when we replace our Sell variable by the Sell net of allocations.
} 
IPO being more likely to buy than sell through the lead underwriters. Table 3 detects a behavior which is consistent with investors breaking the laddering agreement, but it is silent on how relevant this hiding motive is. If laddering is a relevant explanation for hiding sell trades, we should observe a clear positive correlation between hiding behavior (i.e., selling through non-lead brokers) and buying through the lead underwriters.

In order to dig into the drivers of hiding behavior, we decompose trading volume in four parts. Let $V_{i, j}^{T}$ be the total number of shares traded by institution $j$ in IPO $i$ during the first 21 trading days after the issue and let $N_{i}$ be the number of shares issued in IPO $i$. The total volume traded can be written as:

$$
\frac{V_{i, j}^{T}}{N_{i}}=\frac{B_{i, j}^{L}}{N_{i}}+\frac{F_{i, j}^{T}}{N_{i}}+\frac{S_{i, j}^{T}-F_{i, j}^{T}}{N_{i}}+\frac{B_{i, j}^{N L}}{N_{i}}
$$

where $F_{i, j}^{T}$ is the total number of shares of IPO $i$ flipped by institution $j$ during the first 21 trading days, $B_{i, j}^{L}\left(S_{i, j}^{L}\right)$ is the number of shares of IPO $i$ bought (sold) by institution $j$ through the lead underwriters during the first 21 trading days, $B_{i, j}^{N L}$ $\left(S_{i, j}^{N L}\right)$ is the number of shares of IPO $i$ bought (sold) by institution $j$ through brokers other than the lead underwriters during the first 21 trading days, and $B^{T}=B^{L}+B^{N L}$ $\left(S^{T}=S^{L}+S^{N L}\right)$. The third component on the right hand side of the identity, $\left(S_{i, j}^{T}-\right.$ $\left.F_{i, j}^{T}\right) / N_{i}$, is the institution's total volume of "secondary" shares sold, meaning total sales excluding allocations sales, scaled by the number of shares issued. In order to capture the propensity to sell through brokers other than the lead underwriters, we compute the percentage of shares of IPO $i$ sold by institution $j$ through non-lead brokers, $S_{i, j}^{N L} / S_{i, j}^{T}$. Since we are interested in analyzing institutional selling, we constrain our dataset to institutions that have positive sales (i.e., $S_{i, j}^{T}>0$ ). We count 9,018 institution-firm observations.

Under the laddering explanation, institutions tend to sell shares through non-lead brokers, while having bought them in the IPO aftermarket through the lead underwrit- 
ers. Hence, controlling for how the institution normally trades with the lead underwriters (NormalTradeLead), we should observe the percentage of shares sold through non-lead brokers, $S_{i, j}^{N L} / S_{i, j}^{T}$, to be positively correlated with the relative volume of shares bought through the lead underwriters, $B_{i, j}^{L} / N_{i}$, and the relative volume of "secondary" shares sold, $\left(S_{i, j}^{T}-F_{i, j}^{T}\right) / N_{i}$. These predictions are conditional on the institution $j$ having received some allocation in the IPO $i$, as institutions involved in laddering received some allocation in the IPO. Hence, under the laddering motive, these predictions should not hold for institutions with no allocations. Moreover, they should not hold after the first month of trading, when the incentives for institutions to hide their sales become weaker.

In order to test these predictions, we perform a linear projection of the propensity to sell through non-lead brokers on the trading volume components, running several specifications of the following regression:

$$
\frac{S_{i, j}^{N L}}{S_{i, j}^{T}}=\gamma_{0}+\gamma_{1} \frac{B_{i, j}^{L}}{N_{i}}+\gamma_{2} \frac{S_{i, j}^{T}-F_{i, j}^{T}}{N_{i}}+\gamma_{3} \frac{F_{i, j}^{T}}{N_{i}}+\gamma_{4} \frac{B_{i, j}^{N L}}{N_{i}}+X_{i, j} \Gamma+\phi_{i}+\varphi_{j}+v_{i, j}
$$

where $X_{i, j}$ is a vector of control variables (which includes NormalTradeLead ${ }_{i, j}$ and $\left.A l l o c P e r c_{i, j}\right), \phi_{i}$ and $\varphi_{j}$ are firm and institution fixed effects, and $v_{i, j}$ is the error term, which we allow to be correlated within institution. The laddering motive for hiding predicts $\gamma_{1}>0$ and $\gamma_{2}>0$ for institutions that received allocations and trade during the first month after the issue. Table 5 reports the OLS results. All ratios are multiplied by 100, thus being expressed as percentages. We use institution-clustered standard errors for inference. ${ }^{17}$

In Columns (1)-(4), we perform the regression on first-month trading data, including in the sample institutions that received some allocations (i.e., institutions with

\footnotetext{
${ }^{17}$ In unreported analyses, we allow the error term to be correlated within IPO, clustering standard errors at the firm level. The results are consistent.
} 
AllocPerc $\left._{i, j}>0\right)$. Overall results are consistent with the laddering explanation. The coefficients $\gamma_{1}$ and $\gamma_{2}$ are positive in all specifications: institutions tend to execute a higher proportion of their sell trades through non-lead brokers when they buy more shares through the lead underwriters and when they sell more "secondary" shares. According to Column (4), a one unit increase in the volume of shares bought through the lead underwriters (volume of "secondary" shares sold) as a percentage of the amount of shares issued is associated with a 1.24 (2.02) percentage points increase in the proportion of sell trades executed through non-lead brokers. Results are also statistically significant at the $1 \%$ level in most specifications. The specification in column (2), which does not control for fixed effects, shows insignificant or weakly significant results. Firm fixed effects keep IPO characteristics constant, including the identity of the lead underwriters, which might be relevant factors affecting both the propensity to sell and the amount of shares bought in the aftermarket through lead underwriters. For example, some underwriters might have simultaneously a higher proportion of sell trades executed through them and a larger buying activity from investors than other underwriters, thus making it difficult to detect the laddering hiding motive in specifications (1) and (2). ${ }^{18}$ Controlling for IPO fixed effects allows us to keep these factors constant, exploiting within IPO variation. Hence, specifications (3) and (4) are more suitable tests of the laddering motive for hiding.

Consistent with flipping not being a relevant explanation for the Buy/Sell asymmetry we document, we find that $\gamma_{3}$ is negative in most specifications and statistically significant at the $1 \%$ level when controlling for IPO and institution fixed effects: the proportion of shares sold through non-lead brokers is lower when institutions flip more

\footnotetext{
${ }^{18}$ In an unreported analysis, we aggregate data at the lead underwriter level and, indeed, we observe a negative correlation between the proportion of sell trades through non-lead brokers and the volume components of interest, confirming the importance of controlling for IPO fixed effects in our regressions.
} 
of their IPO allocations.

In Column (5) we perform a placebo analysis, including in our sample only the institutions with no IPO allocations (i.e., institutions with AllocPerc $_{i, j}=0$ ). Consistent with the laddering motive for hiding, $\gamma_{1}$ and $\gamma_{2}$ are not statistically different from zero for institutions with no allocations; in addition, $\gamma_{1}$ enters the regression with a negative sign. In column (6) we perform another placebo analysis, running the regression on volumes traded during the third month after the issue. We include in the sample only institutions that received a positive allocation. Consistent with the laddering explanation for hiding, $\gamma_{1}$ and $\gamma_{2}$ are not significantly positive after the first month of trading; both coefficients enter the regression with a negative sign. In addition, $\gamma_{1}$ is statistically significant, consistent with hiding incentives not being at place after the first month.

The remaining volume component, that is the relative amount of shares bought through brokers other than the lead underwriters (BuyNonLead or $\left.B_{i, j}^{N L} / N_{i}\right)$, is in general positively correlated with the proportion of sell trades executed through the lead underwriters, especially in placebo samples. Intuitively, it makes sense: institutions that buy more through non-lead brokers also tend to sell more through non-lead brokers. Noticeably, this positive correlation disappears in specifications (3) and (4), where the laddering hiding motive becomes an important driver of institutional behavior. Unsurprisingly, the coefficient of NormalTradeLead is negative and significant in all specifications, including the placebo analyses: the higher the proportion of trades that the institution usually executes through the lead underwriters, the lower the proportion of sell trades executed through non-lead brokers in IPOs. AllocPerc enters the regression with a positive sign, but only during the first month of trading.

The laddering motive for hiding produces two other testable predictions. First, if institutions that enter in a laddering agreement break it, it has to be the case that they sell the shares that they bought through the lead underwriters. Hence, there should be 
a positive correlation between the volume bought through the lead underwriters and the volume of "secondary" shares sold. Second, since laddering involves an agreement between the lead underwriter and the institution, an institution that engages in laddering is most likely a client of the lead underwriter. Hence, the lead underwriter is going to detect any of its flipping activities thanks to detailed flipping reports. Flipping trades signal to the lead underwriter that the institution sold more shares than it bought in the aftermarket. Hence, flipping trades reveal to the lead underwriter that the institution sold also "secondary" shares through other brokers, thus breaking the laddering agreement, if any. Therefore, institutions that buys through the lead underwriters and wants to hide their "secondary" sales should avoid allocation sales, thus generating a negative correlation between flipping and buying through the lead underwriters. If these correlations are driven by hiding incentives related to laddering, then they should hold only for institutions that received IPO allocations and trade during the first month after the issue.

In order to test these predictions, we regress the amount of net buy through the lead underwriters on the other trading volume components:

$$
\frac{B_{i, j}^{L}-S_{i, j}^{L}}{N_{i}}=\theta_{0}+\theta_{1} \frac{S_{i, j}^{T}-F_{i, j}^{T}}{N_{i}}+\theta_{2} \frac{F_{i, j}^{T}}{N_{i}}+\theta_{3} \frac{B_{i, j}^{N L}}{N_{i}}+X_{i, j} \Gamma+\kappa_{j}+\eta_{i}+\varepsilon_{i, j}
$$

where $X_{i, j}$ is a vector of control variables (which includes NormalTradeLead N $_{i, j}$ and AllocPerc $\left.c_{i, j}\right), \kappa_{j}$ and $\eta_{i}$ are institution and firm fixed effects, and $\varepsilon_{i, j}$ is the error term, which we allow to be correlated within institution. The laddering motive for hiding predicts $\theta_{1}>0$ and $\theta_{2}<0$ for institutions that received allocations and trade during the first month after the issue. We use net buy, $\left(B_{i, j}^{L}-S_{i, j}^{L}\right) / N_{i}$, instead of total buy, $B_{i, j}^{L} / N_{i}$, as dependent variable in order to prevent a mechanical correlation between $B_{i, j}^{L} / N_{i}$ and $\left(S_{i, j}^{T}-F_{i, j}^{T}\right) / N_{i}$ to arise when we control for $B_{i, j}^{N L} / N_{i}$ in the regression. Table 6 reports the OLS results. All ratios are multiplied by 100, thus being expressed 
as percentages. We use institution-clustered standard errors for inference. ${ }^{19}$

In columns (1)-(4), we perform the regression on first-month trading data, including in the sample institutions that received some allocations (i.e., institutions with AllocPerc $\left._{i, j}>0\right)$. Overall, results are consistent with the laddering motive for hiding. The coefficient $\theta_{1}\left(\theta_{2}\right)$ is positive (negative) and statistically significant at the $1 \%$ level in all specifications. Column (4) reports that selling an additional "secondary" shareper-shares-issued is associated with an increase in the net buying through the lead underwriters of 0.33 shares-per-share-issued; flipping an additional share-per-sharesissued is associated with a decrease in the net buying through the lead underwriters of 0.4 shares-per-share-issued.

We perform placebo analyses running the regression on institutions with no allocations (column (5)) and institutions that trade during the third month after the issue (column (6)). Consistent with the correlations in columns (1)-(4) being driven by laddering hiding motives, the coefficients $\theta_{1}$ and $\theta_{2}$ are either insignificant or enter the placebo regressions with the opposite sign.

The remaining volume component, that is the relative amount of shares bought through brokers other than the lead underwriters (BuyNonLead or $\left.B_{i, j}^{N L} / N_{i}\right)$, is positively correlated with the net buy through the lead underwriters in month 3. Intuitively, it makes sense: institutions that buy a stock, buy it through any broker they trade with. Noticeably, this positive correlation disappears in specifications (1)-(4): when laddering and hiding incentives are at place, buying through lead underwriters is not anymore correlated with buying through non-lead brokers. Intriguingly, lead underwriters' usual clients have a significantly lower net buy through the lead underwriters: NormalTradeLead enters the regression with a negative sign. Instead, the coefficient

\footnotetext{
${ }^{19}$ In unreported analyses, we allow the error term to be correlated within IPO, clustering standard errors at the firm level. Results are consistent.
} 
of AllocPerc is positive and statistically significant in month 1 , while being insignificant in month 3. This is broadly consistent with laddering practices (Griffin et al. (2007)): institutions with higher allocations tend to buy more shares through the lead underwriters in the IPO aftermarket. However, an alternative interpretation could be that institutions receive rationed IPO allocations and buy more shares in the aftermarket to reach their optimal holdings. Since we do not observe institutions' bidding behavior, we cannot draw conclusions about the interpretation of the positive correlation between net buy and IPO allocations.

Overall, our evidence suggests that, contrary to the conventional view, allocation sales does not seem to be an important motive for hiding sell trades from the lead underwriters. Instead, we find evidence consistent with the laddering explanation being a relevant driver of institutional hiding behavior.

\section{Alternative explanations and endogeneity issues}

\subsection{Buy/Sell asymmetry: selling more through brokers other than lead underwriters} versus buying more through lead underwriters?

The results of Tables 3 and 4 may be driven by investors buying through the lead underwriters and not necessarily by investors selling through other brokers. If institutions showcase their buy trades to the lead underwriters when entering a laddering agreement, then the coefficient of the regression of LeadDummy on Sell may be downward biased in favor of our hide-and-sell hypothesis. Consequently, the coefficient of the variable AllocationSalesDummy in the regression of LeadDummy on Sell and AllocationSalesDummy may be upward biased in favor of the laddering incentive as opposed to the flipping incentive to hide. To address this concern, we perform an alternative empirical strategy and look at how institutions' trading behavior differ during the 
first month relative to the third month after an IPO. We run the following regressions, conditional on institutions that receive IPO allocations:

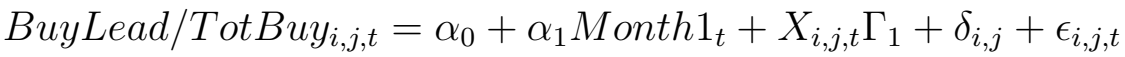

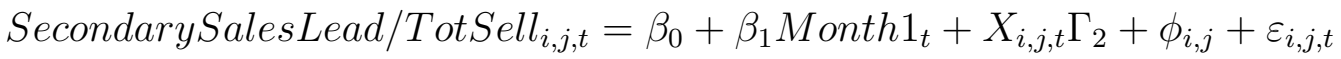

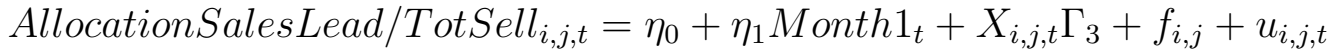

where BuyLead/TotBuy $y_{i, j, t}$ is the percentage of IPO $i$ shares bought by institution $j$ in month $t$ through the lead underwriters of the IPO $i$ in the total amount of shares bought by the same institution $j$ over month $t$; AllocationSales/TotSell $l_{i, j, t}$ is the percentage of allocated shares sold by institution $j$ in month $t$ through the lead underwriters of IPO $i$ from the total amount of allocated shares sold, and SecondarySales/TotSell ${ }_{i, j, t}$ is the percentage of secondary sales of IPO $i$ shares by institution $j$ in month $t$ through the lead underwriters from total secondary sales of of IPO $i .^{20}$ Month $1_{t}$ is a dummy variable equal to one in month 1 and zero in month $3 ; X_{i, j, t}$ is a vector of control variables, which include $\operatorname{RelVol}_{i, j, t}$ and ExcLeadComm ${ }_{i, j, t} ; \delta_{i, j}, \phi_{i, j}$, and $f_{i, j}$ capture institution-firm fixed effects; and $\epsilon_{i, j, t}, \varepsilon_{i, j, t}$, and $u_{i, j, t}$ are the error terms, which we allow to be correlated within institution $j$. All ratios are expressed in percentage terms.

Table 7 reports the results. Columns (1) and (2) suggest that institutions tend to showcase their buy trades to the lead underwriters in the IPO aftermarket. The percentage of buy trades executed through the lead underwriters is about 17 percentage points greater in month 1 than in month 3. Columns (3) and (4) suggest that institutions tend to hide their secondary sales from the lead underwriters in the IPO

\footnotetext{
${ }^{20}$ Since we can compute allocation sales at the daily level, there is some noise when we split an institution's flipping volume by broker type and such institution sells shares through both the lead underwriters and other brokers on a given day. In such cases, we split flipping volume proportionally to the total amount sold by broker type on that day.
} 
aftermarket, consistent with them hiding the breaking of their laddering agreements. The percentage of secondary sales executed through the lead underwriters is about 5 percentage points smaller in month 1 than in month 3. Columns (5) and (6) suggest that institutions do not hide their flipping activity, actually, tend to showcase them to the lead underwriters in the IPO aftermarket. The percentage of allocation sales executed through the lead underwriters is about 11 percentage points greater in month 1 than in month 3 . Overall, these results are consistent with our baseline analyses of sections 3 and 4 .

\subsection{Do lead underwriters charge higher commissions for sell trades?}

An alternative explanation to our findings is the following. Underwriters might try to disincentivize selling of IPO stocks by increasing brokerage commissions selectively on sell trades. If this is the case, some investors might choose to sell through brokers other than lead underwriters in order to save on commissions without any intention to hide their trade. This would generate the buy/sell asymmetry in the choice of the broker observed in our regressions even when the null hypothesis of no hiding behavior holds, thus invalidating our conclusions. Broadly consistent with this argument, Ellis (2006) finds evidence of bookrunners offering better terms on buy trades in a sample of Nasdaq IPOs.

We show that this explanation is unlikely to drive our results. First, we control for the average commission required by lead underwriters in excess of the commission required by other brokers (ExcLeadComm) in our regressions. The variable ExcLeadComm is computed for buy trades and sell trades separately. Hence, it controls for the effect of the potential differential treatment that lead underwriters give to different trades on the investors' probability of choosing a lead underwriter as a broker. Second, we investigate the commissions story more deeply. If the commission story is a 
concern, then we should observe lead underwriters to require higher brokerage commissions for sell trades relative to at least one of these benchmarks: i) lead underwriters' commissions for buy trades in the IPO aftermarket; ii) lead underwriters' commissions for sell trades few months after the IPO; iii) commissions of brokers other than the lead underwriters for sell trades in the IPO aftermarket. We find that Figure 3 and Table 8 show that Figure 3 plots the average trading commission paid to the lead underwriters for buying trades (dark grey line) and sell trades (light grey line) by month from the issue date. Commissions are scaled by the dollar volume traded and $95 \%$ confidence intervals are reported with dotted lines. If anything, average brokerage commissions of lead underwriters are higher for buy trades than for sell trades during the IPO aftermarket. Moreover, average brokerage commissions for sell trades tend to be somewhat higher several months after the IPO than during the first month after the issue date. Table 8 reports difference of means tests for the percentage trading commissions paid to lead underwriters and to any other broker during the first month after the IPO. The table shows that sell trade commissions do not significantly differ among broker types. They do differ, however, for buy trades: lead underwriters require higher commissions for buy trades than other brokers do.

Hence, empirical evidence does not support the commissions story: lead underwriters do not increase commissions on sell trades to disincentivize selling of IPO stocks. In fact, there is some evidence that they might be doing the opposite: commissions on buy trades seem to be particularly high in the IPO aftermarket. ${ }^{21}$ If anything, this

\footnotetext{
${ }^{21}$ Understanding why lead underwriters' commissions on buy trades are high in the IPO aftermarket goes beyond the scope of this paper. Though difficult to reconcile with Ellis (2006)'s result, we notice that our evidence is broadly consistent with the literature on quid-pro-quo agreements in IPOs, which suggest that investors might get preferential treatment in the allocation of IPOs in exchange of paying excessive brokerage commissions to the lead underwriters (e.g., Reuter (2006)). Our finding is also broadly consistent with Griffin et al. (2007), who finds that there is more net buying through the bookrunners in IPOs in which the bookrunner charges higher trading costs.
} 
could actually work against finding results in favor of the hide-and-sell hypothesis.

\subsection{Adressing endogeneity concerns}

The decision to sell is endogenous. Institutions that decide to sell an IPO stock might differ from institutions that buy the IPO under several dimensions that might be correlated with their choice of the broker. In an ideal experiment, we would like to observe how institution $j$ would have traded IPO $i$ if, for a given trade, it would have switched trade side. Since in one of our specifications we exploit within institution-IPO variation, we rule out sources of endogeneity that are constant within institution-IPO pairs (e.g., the relationship between an investor and the lead underwriters of an IPO): we observe the same institution buying and selling the same IPO stock through different brokers, often over the same trading day. ${ }^{22}$ Even though this might seem reasonably close to the ideal experiment mentioned above, we cannot exclude that some tradevarying unobserved factors jointly drive investors' selling and broker choices within institution-IPO pairs. However, it is hard to find a trade-level factor that would make the buy/sell asymmetry in the choice of the broker vanish, given that we control for commissions, volume, and day. Another source of potential criticism is related to the fact that our estimation in column (5) of Table 3 exploits variation in the trading side within institution-IPO pairs. In our sample, more than $50 \%$ of the observations do not exhibit variation within institution-IPO; i.e., the investor is either buying or selling the IPO stock. Hence, in column (5) we use information of a specific subsample of observations. This is unlikely to be a relevant issue for our purposes, as the specification of column (5) still serves the goal of detecting hiding behavior. Moreover, the coefficient of Sell in the regressions of Table 3 is fairly stable across different specifications, in-

\footnotetext{
${ }^{22}$ We observe an institution $j$ trading the same stock $i$ through several distinct brokers $b$ during the same trading day $t$ for $23 \%$ of the observations.
} 
cluding column (5). Overall, even though we do not claim that we estimate a causal effect, endogeneity concerns are unlikely to qualitatively change our conclusions about the buy/sell asymmetry in the choice of the broker.

For robustness, we also seek for a source of exogenous variation in the selling decision of financial institutions. Funds in distress, which experience large outflows, tend to decrease their existing positions (Coval and Stafford (2007)), including their IPO holdings. Hence, institutions that manage funds in distress are more likely to sell IPO shares. This suggests a candidate instrument for financial institutions' selling decisions: the number of funds in distress managed by the institution. This instrument is plausibly exogenous in this setting, as funds' distress is likely unrelated with the probability of the institution trading through the lead underwriters of a given IPO. ${ }^{23}$ Moreover, underwriters usually allocate shares to fund families, which then decide how to distribute them within the family (Ritter and Zhang (2007)). This lowers the scope for direct links between distressed funds and the institution's choice to trade through the underwriters in the IPO aftermarket.

We use clientcode-clientmgrcode pairs in the Abel Noser Solutions' database to identify distinct funds managed by our sample institutions. ${ }^{24}$ We define a fund to be in distress in a given month if two conditions are met: 1) more than $99 \%$ of its trading

\footnotetext{
${ }^{23} \mathrm{~A}$ theoretically possible channel that could invalidate the exogeneity assumption is that institutions with several funds in distress might be institutions with little or no connections with important brokers, which also underwrite IPOs. Under this "connection" argument, institutions with distressed funds would tend to trade more with non-lead brokers regardless of the side of the trade. We find no evidence in this direction: the number of distressed funds of an institution is not significantly correlated with its normal number of trades executed through the lead underwriters in non-IPO stocks (NormalTradeLead).

${ }^{24}$ From our talks with ANcerno it became clear that clientmgrcode identifies individual funds, fund managers, or separately managed accounts (see also Hu et al. (2018)). Clientmgrcode is provided by the client and may change over time, ANcerno however reassured us that clientmgrcode remains unchaged within each a batch of data provided by the client (identified by the lognumber). For this reason, we follow Eisele et al. (2017) and use a couple clientcode-clientmgrcode to separate among individual funds.
} 
volume in non-IPO stocks is due to sell trades; 2) the monthly dollar volume traded by the fund in non-IPO stoks is above the 90th percentile. The idea is that funds with large selling volumes are likely experiencing a fire-sale event. Our institution-level distress variable, LnDistressFunds $s_{i, j}$, is the natural logarithm of the number of funds in distress managed by institution $j$ during the month in which the IPO $i$ is made. We use it as instrumental variable for Sell. Table 9 reports the 2SLS results, which are qualitatively consistent with our baseline regressions.

The results of Table 9 have to be taken cautiously. We acknowledge that they are sensitive to the choice of the dollar volume threshold: the instrument becomes weak when we set lower thresholds, such as the 50th or the 75 th percentiles of the monthly volume traded. Even though it make sense that only large transaction volumes are related to fire-sales events that could be relevant in the first stage regression, we cannot justify the choice of a specific volume threshold to build our variable. Table 9 suggests that endogeneity concerns do not seem to qualitatively change our conclusions, but the potential weakness of the instrument does not allow us to make strong causal statements.

\section{Is the hiding strategy effective?}

In this section we test whether selling through non-lead brokers allow institutional clients to be less penalized in future IPO allocations from the lead underwriter. According to Chemmanur et al. (2010), institutions that flip their shares receive fewer allocations in subsequent IPOs. We develop our predictions following their findings, and investigate whether institutions that employ the hiding strategy and sell their shares through non-lead brokers, manage to circumvent underwriters' penalty in terms of share allocations. It is important to assess if the hiding strategy is indeed: 1) beneficial for the institution; 2) costly for the IPO process, as allocations might be suboptimal. To 
test our predictions, we estimate Arellano-Bond regressions with difference-GMM of IPO allocations on the selling transactions executed by institutions lead underwriters and non-lead brokers using the following model:

$$
\begin{aligned}
\text { AvgPercAlloc }_{j, t} & =\beta_{0}+\beta_{1} \text { AvgSecondarySalesLead }_{j, t-1} \\
& +\beta_{2} \text { SecondarySalesNonLead }_{j, t-1}+[\ldots]+X_{j, t-1} \Gamma+\delta_{j}+\tau_{t}+\epsilon_{j, t}
\end{aligned}
$$

where AvgAllocPerc is the average percentage IPO allocation received by the institution in a 6-months period as a portion of total shares offered in an IPO. Our variables of interest are L.AvgSecondarySalesLead (L.AvgSecondarySalesNonLead) that is lagged 6-months average relative share volume of secondary sales executed through lead brokers (non-lead brokers). Other variables included in the model are the average lagged 6-month trading volume components scaled by the number of shares issued: L.AvgBuyLead (L.AvgBuyNonLead) is the average relative number of shares bought through the lead underwriters (non-lead brokers); L.AvgAllocationSalesLead (L.AvgAllocationSalesNonLead) is the relative number of allocated shares sold through lead brokers (non-lead brokers). $X_{j, t-1}$ is a vector of control variables: NormalTradeLead ${ }_{j, t-1}$ and the lagged AvgAllocPerc. $\delta_{j}$ are institution fixed effects, $\tau_{t}$ are semi-annual fixed effects, and $\epsilon_{i, t}$ is the error term, which we allow to be correlated within institution.

Table 9 reports the results on the regression analysis of IPO allocations received by institutions in our sample. All ratios are multiplied by 100. The results confirm that institutions selling IPO shares through lead underwriters receive fewer allocations (as a fraction of the number of shares issued). According to Column (4), the coefficient on L.AvgSecondarySalesLead is negative and significant. A one unit increase in the volume of secondary shares sold through lead underwriters is associated with a 6.42 percentage points decrease in the proportion of allocated shares to the institution in 
the following 6-month period. The coefficient on L.AvgSecondarySalesNonLead is insignificant, confirming the hypothesis that institutions hiding their sells with nonlead brokers are unlikely to be penalized for their selling.

In Column (2) we control for NormalTradeLead - the \% volume of sell or buy trades in non-IPO stocks made by the institution through the lead underwriters in a 6-month period prior to the issues. Columns (3) and (4) include semi-annual fixed effects. Columns (1)-(3) use one-lag instruments, Column (4) includes one-lag and two-lag instruments. The results are qualitatively similar in all specifications.

Overall, our findings support the idea that the choice of the broker for selling IPO shares can be an effective way to bypass the underwriters' attention and avoid the penalty in terms of future allocations. Selling IPO shares in the amount that does not exceed the amount of shares bought by the institution in the aftermarket allows institutions to avoid a penalty in terms of share allocation that a lead underwriter may impose on institutions otherwise. The incentives to punish and hide selling trades seem to be present only for secondary sales, they do not seem to be pronounced for allocations sales.

\section{Conclusion}

We document that institutional investors are less likely to sell than buy through lead underwriters in the aftermarket of IPOs issued between 1999 and 2010 in the United States. The probability of trading through a lead underwriter during the first month after the issue is about 6 percentage points less for sell trades than for buy trades. This result holds when controlling for important determinants of the choice to trade with a lead underwriter, such as the relationship between the institution and the lead underwriters, and is robust to institution, IPO, and institution-IPO fixed effects. We find that the documented buy/sell asymmetry varies consistently with hiding incentives: 
it is stronger when the aftermarket demand for IPO stocks is weaker (i.e., in cold IPOs), it does not hold after the first month of trading, and it does not hold for a matched sample of non-IPO stocks.

We rule out potential alternative explanations for the buy/sell asymmetry. Our findings are not driven by underwriters' strategically setting differential brokerage commissions to disincetivize sell trades. Moreover, our evidence suggests that the buy/sell asymmetry is not only driven by investors buying more through the lead underwriters, but also by investors selling less through the lead underwriters. Finally, potential endogeneity concerns are unlikely to make the buy/sell asymmetry vanish and we find evidence consistent with this view in an IV setting, using a proxy for institutional fire-sales as exogenous shock for the decision to sell an IPO.

We investigate the motives behind institutional investors' hiding behavior. Contrary to the conventional view, we find that flipping IPO allocations is not an important motive for hiding sell trades from the lead underwriters. This is reasonable, as underwriters have access to reports that document investors' flipping activity. We propose and test a novel explanation of the buy/sell asymmetry in the choice of the broker in IPO aftermarket. We find evidence in favor of this explanation. Institutional investors that agree with the underwriters to buy additional shares in the IPO aftermarket in exchange of receiving allocations (a practice known as "laddering"), might break this agreement by hiding-and-selling the shares bought in the aftermarket through other brokers. Consistent with the laddering explanation, we find that: i) the percentage of sell volume executed through non-lead brokers is higher when institutional investors buy more shares through the lead underwriters in the IPO aftermarket and when institutional investors execute more "secondary" sales (i.e., sales other than allocation sales); and ii) the volume of "secondary" shares sold in the aftermarket by an institution is positively correlated with its net buy volume through the lead underwriters. 
Moreover, an investor that hide his/her sell trades because of the laddering agreement should avoid flipping trades. These trades signal to the lead underwriters that the investor sold more shares than it bought in the aftermarket, thus revealing that it has broken the laddering agreement. Consistently, we find a negative correlation between the allocation sales volume of an institution and its net buy volume through the lead underwriters.

We show that hiding sell trades is an effective strategy to circumvent underwriters' monitoring mechanisms: the more institutions hide their sell trades, the less they are penalized in subsequent IPO allocations.

Our evidence sheds light on how hiding incentives affect institutions' choice of their broker in the IPO aftermarket and stimulates further research to investigate how the incentives of IPO investors may influence the IPO allocation process. 


\section{References}

Aggarwal, R., 2000. Stabilization activities by underwriters after Initial Public Offerings. The Journal of Finance 55, 1.

Aggarwal, R., 2003. Allocation of initial public offerings and flipping activity. Journal of Financial Economics 68, 111-135.

Benveniste, L.M., Spindt, P.A., 1989. How investment bankers determine the offer price and allocation of new issues. Journal of Financial Economics 24, 343-361.

Benveniste, L.M., Wilhelm, W.J., 1990. A comparative analysis of ipo proceeds under alternative regulatory environments. Journal of Financial Economics 28, 173-207.

Chemmanur, T.J., Hu, G., Huang, J., 2010. The role of institutional investors in initial public offerings. The Review of Financial Studies 23, 4496-4540.

Cornelli, F., Goldreich, D., 2001. Bookbuilding and strategic allocation. The Journal of Finance 56, 2337-2369.

Corwin, S.A., Schultz, P., 2005. The role of IPO underwriting syndicates: pricing, information production, and underwriter competition. The Journal of Finance 60, $443-486$.

Coval, J., Stafford, E., 2007. Asset fire sales (and purchases) in equity markets. Journal of Financial Economics 86, 479-512.

Eisele, A., Nefedova, T., Parise, G., Peijnenburg, K., 2017. Trading out of sight: an analysis of cross-trading in mutual fund families. Centre for Economic Policy Research 
Ellis, K., 2006. Who trades IPOs? a close look at the first days of trading. Journal of Financial Economics 79, 339-363.

Ellis, K., Michaely, R., O'Hara, M., 2000. When the underwriter is the market maker: an examination of trading in the IPO aftermarket. The Journal of Finance 55, 1039 1074.

Goldstein, M.A., Irvine, P., Kandel, E., Wiener, Z., 2009. Brokerage commissions and institutional trading patterns. The Review of Financial Studies 22, 5175-5212.

Goldstein, M.A., Irvine, P., Puckett, A., 2011. Purchasing IPOs with commissions. Journal of Financial and Quantitative Analysis 46, 1193-1225.

Griffin, J.M., Harris, J.H., Topaloglu, S., 2007. Why are IPO investors net buyers through lead underwriters? Journal of Financial Economics 85, 518-551.

Hao, Q., 2007. Laddering in initial public offerings. Journal of Financial Economics 85, $102-122$.

Horrace, W.C., Oaxaca, R.L., 2006. Results on the bias and inconsistency of ordinary least squares for the linear probability model. Economic Letters 90, 321-327.

Hu, G., Jo, K., Wang, Y.A., Xie, J., 2018. Institutional trading and Abel Noser Data. Journal of Corporate Finance 52, 143-167.

Hwang, C.Y., Titman, S., Wang, Y., 2018. Is it who you know or what you know? evidence from IPO allocations and mutual fund performance. Journal of Financial and Quantitative Analysis 53, 2491-2523.

Jenkinson, T., Jones, H., 2004. Bids and allocations in European IPO bookbuilding. The Journal of Finance 59, 2309-2338. 
Jenkinson, T., Jones, H., 2009. IPO pricing and allocation: a survey of the views of institutional investors. The Review of Financial Studies 22, 1477-1504.

Jenkinson, T., Jones, H., Suntheim, F., 2017. Quid pro quo? What factors influence IPO allocations and pricing? The Journal of Finance forthcoming.

Liu, X., Ritter, J.R., 2010. The economic consequences of IPO spinning. The Review of Financial Studies 23, 2024-2059.

Loughran, T., Ritter, J.R., 2004. Why has IPO underpricing changed over time? Financial Management 33, 5-37.

Lowry, M., Michaely, R., Volkova, E., 2017. Initial public offerings: a synthesis of the literature and directions for future research. Foundations and Trends in Finance forthcoming.

Nimalendran, M., Ritter, J.R., Zhang, D., 2007. Do today's trades affect tomorrow's IPO allocations? Journal of Financial Economics 84, 87-109.

Reuter, J., 2006. Are IPO allocations for sale? Evidence from mutual funds. The Journal of Finance 61, 2289-2324.

Ritter, J.R., 2011. Equilibrium in the initial public offerings market. Annual Review of Financial Economics 3, 347-374.

Ritter, J.R., Zhang, D., 2007. Affiliated mutual funds and the allocation of initial public offerings. Journal of Financial Economics 86, 337-368.

Sherman, A.E., 2000. Ipos and long-term relationships: an advantage of bookbuilding. The Review of Financial Studies 13, 697-714. 
Sherman, A.E., Titman, S., 2002. Building the IPO order book: underpricing and participation limits with costly information. Journal of Financial Economics 65, 329 . 


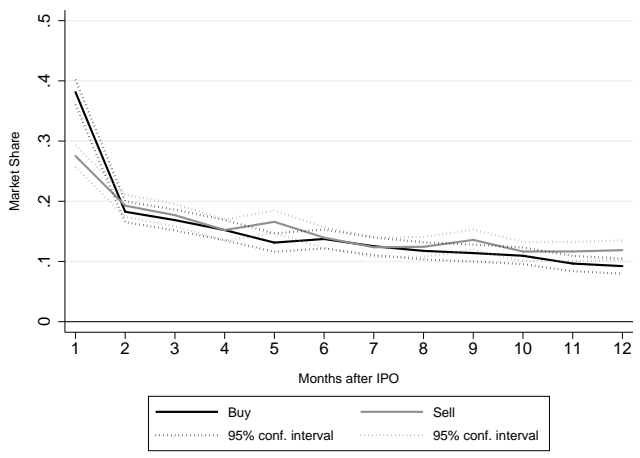

(a) All IPOs

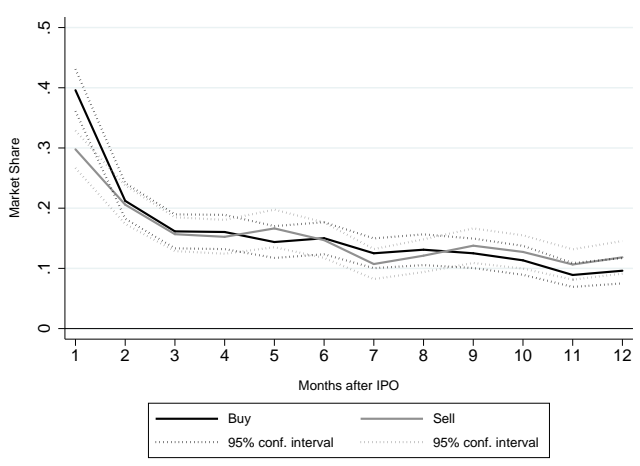

(c) Weak IPOs

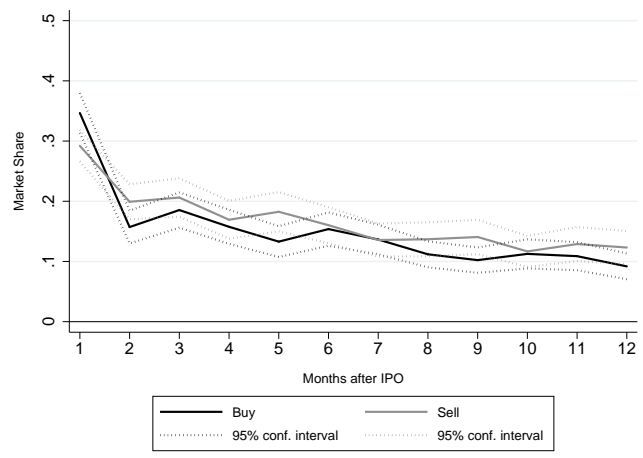

(b) Hot IPOs

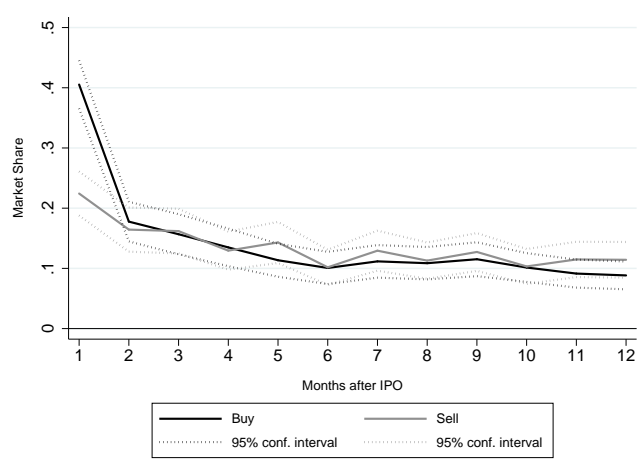

(d) Cold IPOs

Fig. 1. Average lead UW market share for different levels of underpricing. This figure shows the average brokerage market share for buy trades (dark grey lines) and sell trades (light grey lines) of the lead underwriters by month from the IPO date. For each IPO, we compute the percentage of institutional buy and sell trades executed by the lead underwriters in each month from the IPO date; then we average these percentages across IPO and we compute $95 \%$ confidence intervals of the means (dashed lines). Panels (A) reports the brokerage market share for all IPOs. Panel (B) reports the brokerage market share for hot IPOs (highest tercile of Underpricing); Panels (C) reports the brokerage market shares for weak IPOs (middle tercile of Underpricing); and Panels (D) reports the brokerage market share for cold IPOs (lowest tercile of Underpricing). 


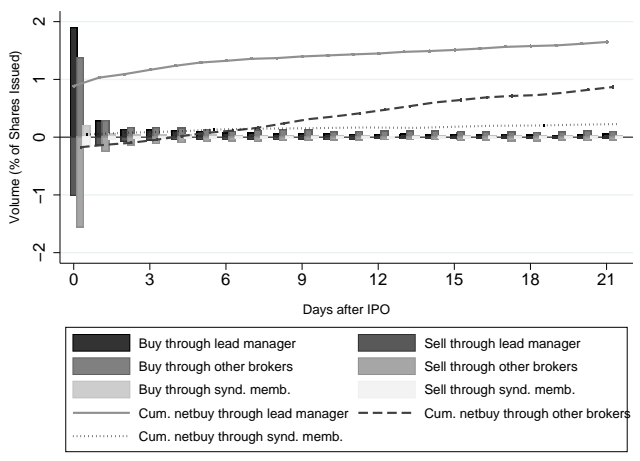

(a) All IPOs

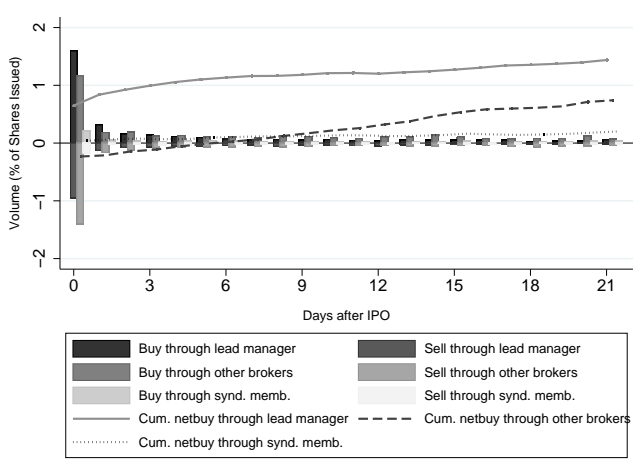

(c) Weak IPOs

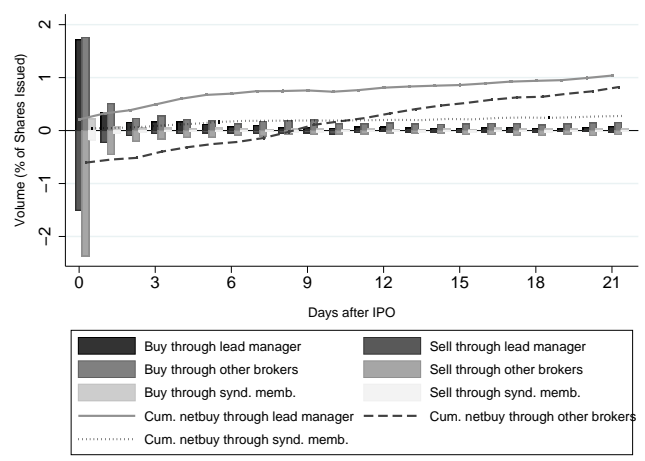

(b) Hot IPOs

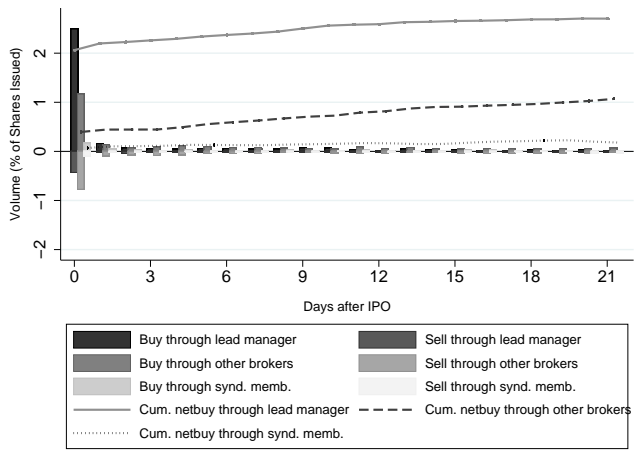

(d) Cold IPOs

Fig. 2. Average cumulative netbuy and buy/sell volume in the first 21 trading days after IPO issue date. For each IPO, we compute the total amount bought and sold in each day by institutions that trade through the lead underwriters, through other syndicate members, and through brokers that did not participate in the IPO syndicate. We also compute the cumulative netbuy of lead managers' clients, syndicate members' clients, and other brokers' clients in the first 21 trading days after the IPO. We scale the volume traded by the number of shares issued and we average it across IPOs. Bars show institutions' daily volume bought and sold; lines plot institutions' cumulative netbuy. Panel (A) averages buy and sell volumes and cumulative netbuy for all IPOs. Panels (B)-(D) break the averages down for hot IPOs (highest tercile of Underpricing), weak IPOs (middle tercile of Underpricing), and cold IPOs (lowest tercile of Underpricing). 


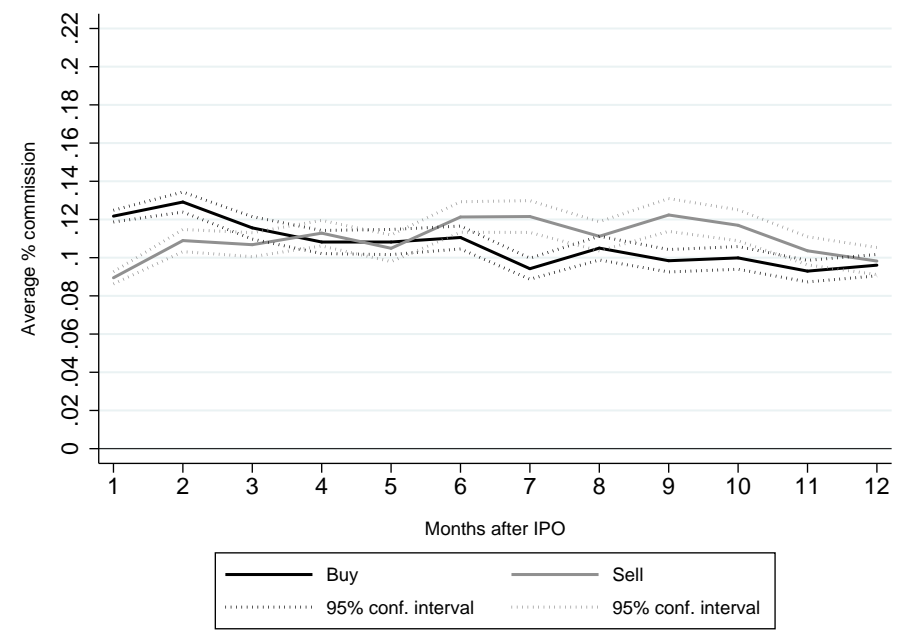

Fig. 3. Average trading commissions. This figure plots the average trading commission paid to the lead underwriters for buying trades (dark grey line) and sell trades (light grey line) by month from the issue date. Commissions are scaled by the dollar volume traded. $95 \%$ confidence intervals are reported with dotted lines. 


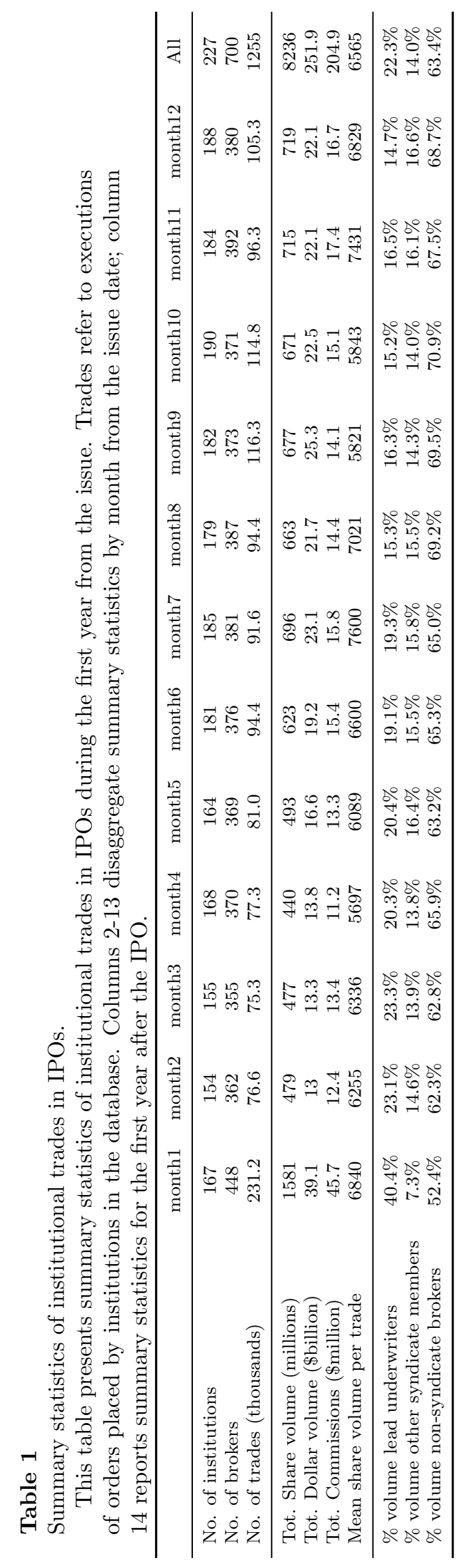


Table 2

Summary statistics of IPO allocations by institution and by issuer.

This table provides IPO allocations summary statistics at the institution level (AllocPerc) and issuer level (Number of Allocations; Total \% Institutional Allocation). AllocPerc is the percentage of IPO shares allocated to an institution (winsorized at the $95 \%$ level). The table reports summary statistics for all IPOs and for subsamples of IPOs based on Underpricing terciles: hot IPOs (highest tercile), weak IPOs (middle tercile), and cold IPOs (lowest tercile). For each variable, the table reports its average (mean), its median (p50), and its standard deviation (sd).

\begin{tabular}{lccc}
\hline \hline & mean & $\mathrm{p} 50$ & $\mathrm{sd}$ \\
\hline AllocPerc (all IPOs) & 1.89 & 0.54 & 3.05 \\
AllocPerc (hot IPOs) & 1.53 & 0.40 & 2.71 \\
AllocPerc (weak IPOs) & 1.98 & 0.67 & 3.02 \\
AllocPerc (cold IPOs) & 2.53 & 0.78 & 3.67 \\
\hline Number of Allocations (all IPOs) & 22.7 & 21 & 14.4 \\
Number of Allocations (hot IPOs) & 30.6 & 30 & 13.9 \\
Number of Allocations (weak IPOs) & 23.7 & 22 & 13.6 \\
Number of Allocations (cold IPOs) & 13.6 & 12 & 10.1 \\
\hline Total \% Institutional Allocation (all IPOs) & 42.7 & 42.5 & 21.7 \\
Total \% Institutional Allocation (hot IPOs) & 47.0 & 45.6 & 23.1 \\
Total \% Institutional Allocation (weak IPOs) & 46.9 & 47.3 & 20.6 \\
Total \% Institutional Allocation (cold IPOs) & 34.3 & 33.9 & 18.7 \\
\hline \hline
\end{tabular}


.

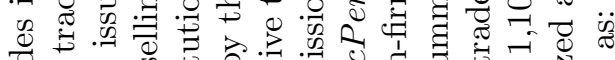

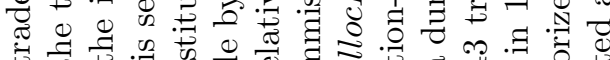

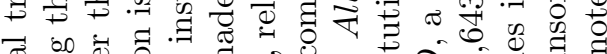

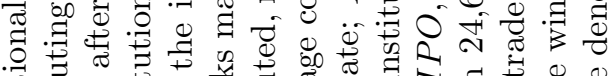

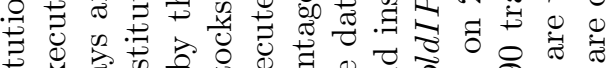

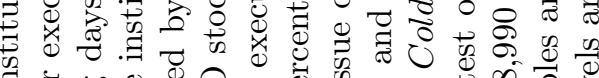

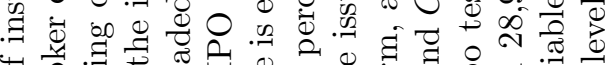

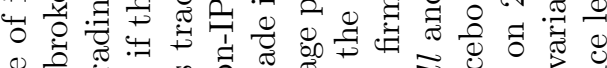

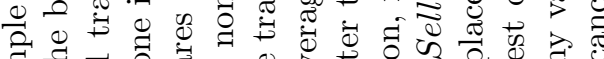

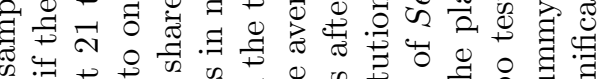
w

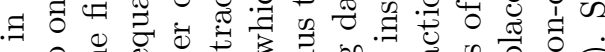

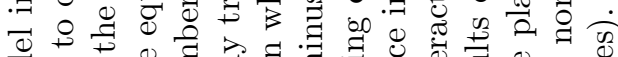

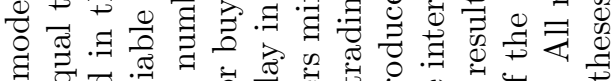

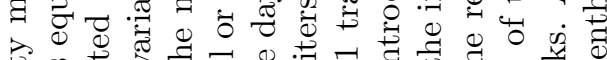
. 完 है औ छ

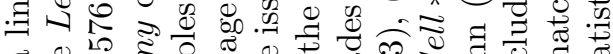

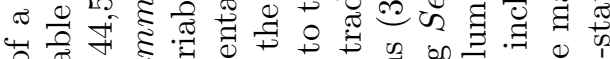
○.

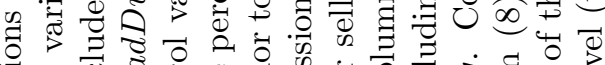

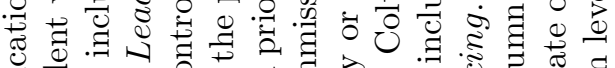

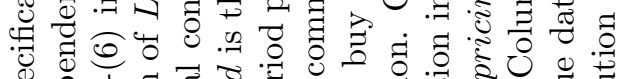
ن की

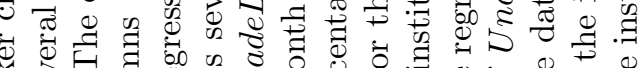

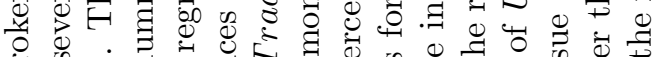

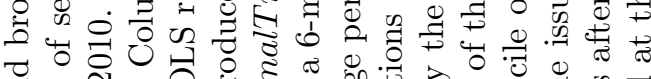

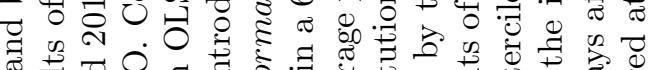

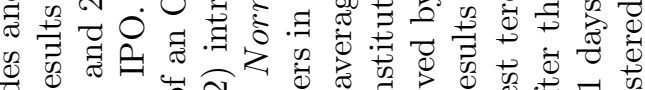

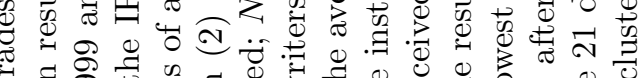

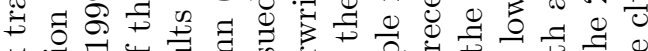

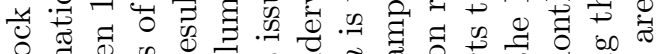

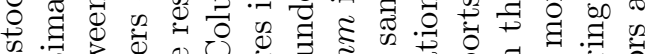

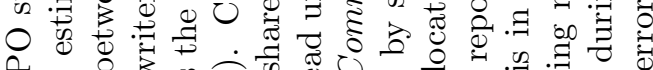

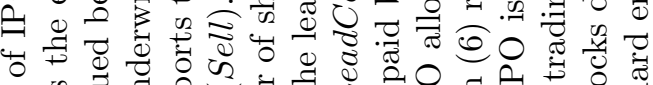

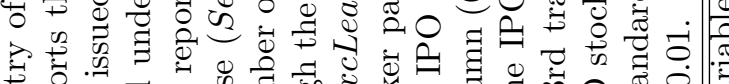

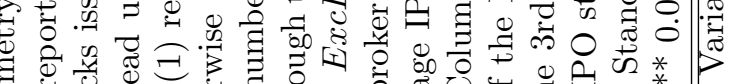

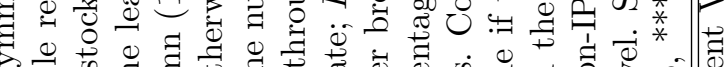

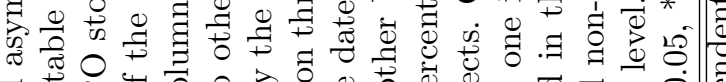

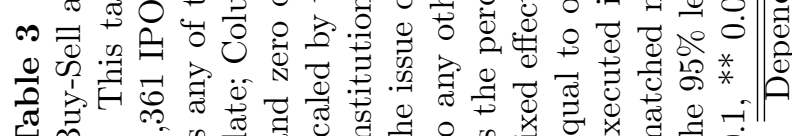

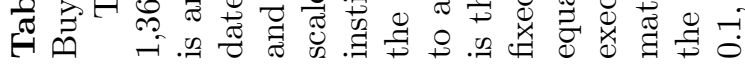

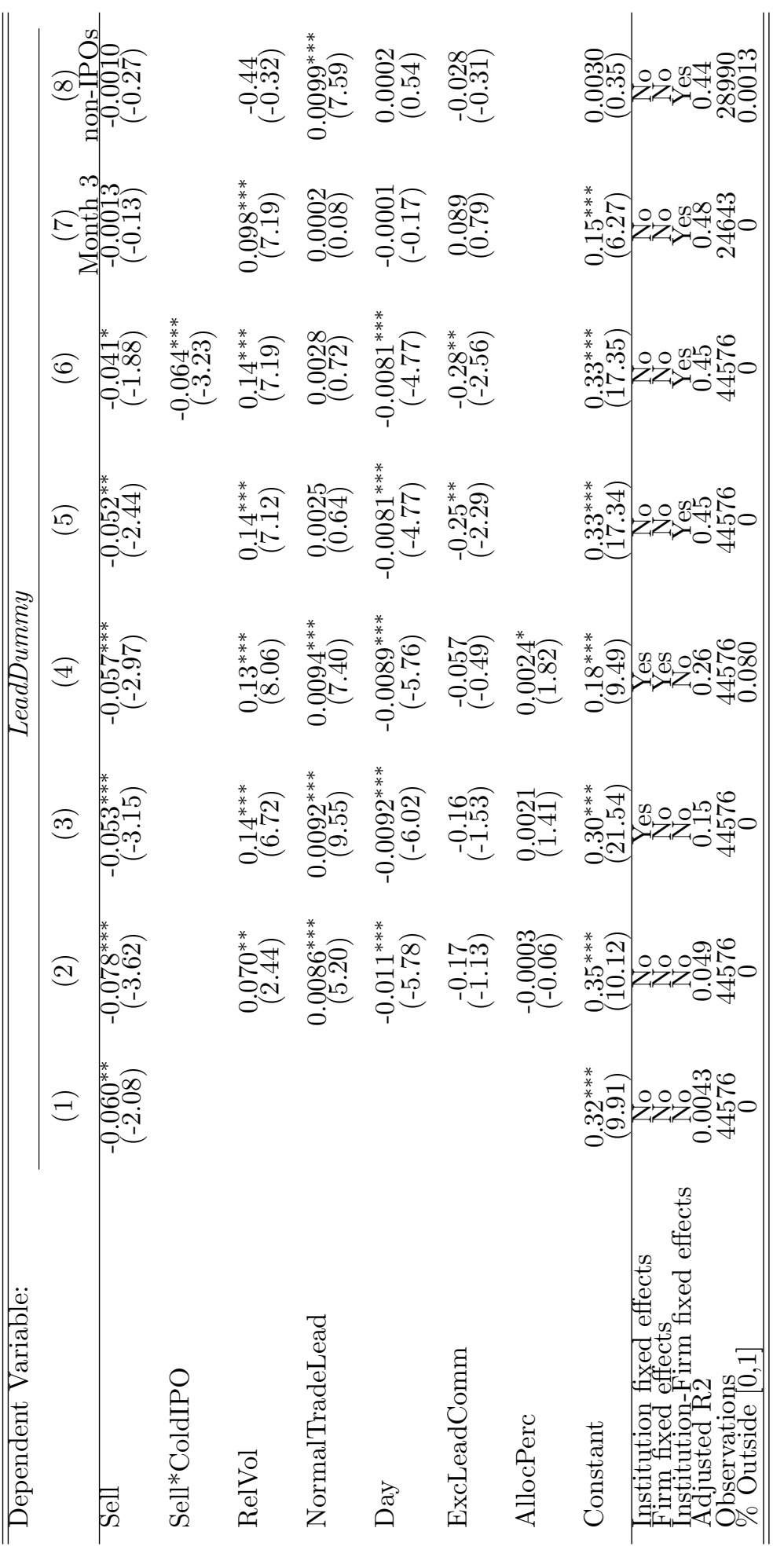


Table 4

What drives the Buy/Sell asymmetry: allocation sales vs secondary sales?

This table reports the estimation results of several specifications of a linear probability model in a sample of institutional trades in 1,361 IPO stocks issued between 1999 and 2010. The sample includes 44,576 trades executed in the first 21 trading days after the issue date. The dependent variable is a dummy equal to one if the broker executing the trade is any of the lead underwriters of the IPO (LeadDummy). Column (1) reports the results of an OLS regression of LeadDummy on a dummy variable equal to one if the institution is selling and zero otherwise (Sell) and a dummy variable equal to one if the sell trade contains an allocation sale and zero otherwise (AllocationSalesDummy). Column (2) introduces several control variables: RelVol is the number of shares traded by the institution scaled by the number of shares issued; NormalTradeLead is the percentage volume of sell or buy trades in non-IPO stocks made by the institution through the lead underwriters in a 6-month period prior to the issue; Day is the day in which the trade is executed, relative to the issue date; ExcLeadComm is the average percentage commission to the lead underwriters minus the average percentage commission to any other broker paid by sample institutions for their buy or sell trades in the first 21 trading days after the issue date; AllocPerc is the percentage IPO allocation received by the institution. Columns (3), (4), and (5) introduce institution, firm, and institution-firm fixed effects. All non-dummy variables are winsorized at the 95\% level. Standard errors are clustered at the institution level (t-statistics are in parentheses). Significance levels are denoted as: $* 0.1,{ }^{*} 0.05, * * * 0.01$.

\begin{tabular}{|c|c|c|c|c|c|}
\hline Dependent Variable: & \multicolumn{5}{|c|}{ LeadDummy } \\
\hline Sell & $\begin{array}{c}(1) \\
-0.15^{* * *} \\
(-5.40)\end{array}$ & $\begin{array}{c}(2) \\
-0.14^{* * *} \\
(-5.65)\end{array}$ & $\begin{array}{c}(3) \\
-0.087^{* * *} \\
(-4.47)\end{array}$ & $\begin{array}{c}(4) \\
-0.081^{* * *} \\
(-3.84)\end{array}$ & $\begin{array}{c}(5) \\
-0.076^{* * *} \\
(-3.62)\end{array}$ \\
\hline AllocationSaleDummy & $\begin{array}{c}0.12^{* * *} \\
(5.71)\end{array}$ & $\begin{array}{c}0.074^{* * *} \\
(3.98)\end{array}$ & $\begin{array}{c}0.045^{* * *} \\
(3.94)\end{array}$ & $\begin{array}{c}0.034^{* * *} \\
(2.88)\end{array}$ & $\begin{array}{c}0.059^{* * *} \\
(2.76)\end{array}$ \\
\hline Controls & No & Yes & Yes & Yes & Yes \\
\hline Institution fixed effects & No & No & Yes & Yes & No \\
\hline Firm fixed effects & No & No & No & Yes & No \\
\hline Institution-Firm fixed effects & No & No & No & No & Yes \\
\hline Adjusted R2 & 0.0093 & 0.051 & 0.15 & 0.26 & 0.45 \\
\hline Observations & 44576 & 44576 & 44576 & 44576 & 44576 \\
\hline$\%$ Outside $[0,1]$ & 0 & 0.00070 & 0 & 0.080 & 0 \\
\hline
\end{tabular}




\section{Table 5}

The determinants of selling through brokers other than lead underwriters.

This table reports the estimates of an OLS regression of SellNonLead - the volume of sales executed through brokers other than the lead underwriter as a percentage of total sales $\left[S_{i, j}^{N L} / S_{i, j}^{T}\right]$ on the trading volume components scaled by the number of shares issued: BuyLead is the relative number of shares bought through the lead underwriters $\left[B_{i, j}^{L} / N_{i}\right] ;$ SecondarySales is the relative volume of sales other than allocation sales $\left[\left(S_{i, j}^{T}-F_{i, j}^{T}\right) / N_{i}\right]$; AllocationSales is the relative number of shares flipped $\left[F_{i, j}^{T} / N_{i}\right]$; and BuyNonLead is the relative number of shares bought through nonlead brokers $\left[B_{i, j}^{N L} / N_{i}\right]$. Control variables are described in Table 3. All ratios are multiplied by 100. Columns (1)-(4) include trades executed during the first month after the issue by institutions that received an IPO allocation. Column (5) includes trades executed during the first month after the issue by institutions with no IPO allocations. Column (6) includes trades executed during the third month after the issue by institutions that received an IPO allocation. Standard errors are clustered at the institution level (t-statistics are in parentheses). Significance levels are denoted as: $* 0.1, * * 0.05, * * * 0.01$.

\begin{tabular}{lcccccc}
\hline \hline Dependent Variable: & \multicolumn{5}{c}{ SellNonLead } \\
\cline { 2 - 7 } & $(1)$ & $(2)$ & $(3)$ & $(4)$ & $(5)$ & $(6)$ \\
& $1.12^{*}$ & 0.41 & $1.64^{* * *}$ & $1.24^{* * *}$ & No-allocations & Month 3 \\
\hline BuyLead & $(1.75)$ & $(0.58)$ & $(4.60)$ & $(3.50)$ & $(-0.37$ & $-2.24^{* *}$ \\
& $1.74^{* * *}$ & $1.22^{*}$ & $3.11^{* * *}$ & $2.02^{* * *}$ & 0.92 & $(-2.08)$ \\
SecondarySales & $(2.77)$ & $(1.78)$ & $(3.29)$ & $(2.83)$ & $(0.42)$ & -0.96 \\
& & & & $(-1.01)$ \\
AllocationSales & 0.23 & $-1.48^{*}$ & -0.14 & $-1.93^{* * *}$ & & 0.41 \\
& $(0.28)$ & $(-1.87)$ & $(-0.14)$ & $(-3.15)$ & & $(0.45)$ \\
BuyNonLead & $1.55^{* * *}$ & $1.18^{* *}$ & 0.40 & -0.045 & $1.56^{*}$ & $3.30^{* * *}$ \\
& $(2.71)$ & $(2.52)$ & $(0.80)$ & $(-0.11)$ & $(1.93)$ & $(4.96)$ \\
NormalTradeLead & $-3.81^{* * *}$ & $-3.86^{* * *}$ & $-4.43^{* * *}$ & $-3.96^{* * *}$ & $-2.17^{*}$ & $-3.12^{* * *}$ \\
& $(-14.61)$ & $(-15.06)$ & $(-19.52)$ & $(-18.52)$ & $(-1.95)$ & $(-9.04)$ \\
AllocPerc & & $1.99^{* * *}$ & $1.41^{* * *}$ & $0.82^{* * *}$ & & 0.24 \\
& & $(6.90)$ & $(4.37)$ & $(3.21)$ & & $(1.15)$ \\
Constant & $75.2^{* * *}$ & $73.9^{* * *}$ & $75.4^{* * *}$ & $62.2^{* * *}$ & $84.0^{* *}$ & $78.7^{* * *}$ \\
& $(34.32)$ & $(33.25)$ & $(33.91)$ & $(16.55)$ & $(2.60)$ & $(11.63)$ \\
\hline Institution fixed effects & No & No & Yos & Yes & Yes & Yes \\
Firm fixed effects & 0.20 & 0.20 & 0.32 & 0.41 & 0.33 & 0.34 \\
Adjusted R2 & 8539 & 8539 & 8539 & 8539 & 479 & 2421 \\
Observations & \multicolumn{7}{c}{} \\
\hline \hline
\end{tabular}




\section{Table 6}

The determinants of the net-buying volume through lead underwriters.

This table reports the estimates of an OLS regression of NetBuyLead - the net buy volume through the lead underwriters scaled by the number of shares issued $\left[\left(B_{i, j}^{L}-S_{i, j}^{L}\right) / N_{i}\right]$ on other trading volume components scaled by the number of shares issued: SecondarySales is the relative volume of sales other than allocation sales $\left[\left(S_{i, j}^{T}-F_{i, j}^{T}\right) / N_{i}\right]$; AllocationSales is the relative number of shares flipped $\left[F_{i, j}^{T} / N_{i}\right]$; and BuyNonLead is the relative number of shares bought through nonlead brokers $\left[B_{i, j}^{N L} / N_{i}\right]$. Control variables are described in Table 3. All ratios are multiplied by 100. Columns (1)-(4) include trades executed during the first month after the issue by institutions that received an IPO allocation. Column (5) includes trades executed during the first month after the issue by institutions with no IPO allocations. Column (6) includes trades executed during the third month after the issue by institutions that received an IPO allocation. Standard errors are clustered at the institution level (t-statistics are in parentheses). Significance levels are denoted as: $* 0.1, * * 0.05, * * * 0.01$.

\begin{tabular}{|c|c|c|c|c|c|c|}
\hline \multirow[t]{2}{*}{ Dependent Variable: } & \multicolumn{6}{|c|}{ NetBuyLead } \\
\hline & (1) & $(2)$ & (3) & (4) & $(5)$ & (6) \\
\hline SecondarySales & $\begin{array}{c}0.31^{* * *} \\
(8.43)\end{array}$ & $\begin{array}{c}0.28^{* * *} \\
(7.31)\end{array}$ & $\begin{array}{c}0.35^{* * *} \\
(5.97)\end{array}$ & $\begin{array}{c}0.33^{* * *} \\
(5.49)\end{array}$ & $\begin{array}{c}\text { No-allocations } \\
0.20 \\
(0.67)\end{array}$ & $\frac{\text { Month } 3}{-0.20^{* * *}}$ \\
\hline AllocationSales & $\begin{array}{c}-0.30^{* * *} \\
-6.81)\end{array}$ & $\begin{array}{c}-0.36^{* * *} \\
-6.80)\end{array}$ & $\begin{array}{c}-0.36^{* * *} \\
(-9.45)\end{array}$ & $\begin{array}{c}-0.40^{* * *} \\
(-8.25)\end{array}$ & & $\begin{array}{c}-0.018 \\
(-0.30)\end{array}$ \\
\hline BuyNonLead & $\begin{array}{c}0.00013 \\
(0.00)\end{array}$ & $\begin{array}{l}-0.011 \\
(-0.34)\end{array}$ & $\begin{array}{l}-0.023 \\
(-0.59)\end{array}$ & $\begin{array}{l}-0.028 \\
(-0.68)\end{array}$ & $\begin{array}{l}-0.028 \\
(-0.21)\end{array}$ & $\begin{array}{c}0.44^{* * *} \\
(9.48)\end{array}$ \\
\hline NormalTradeLead & $\begin{array}{c}-0.0051^{*} \\
(-1.73)\end{array}$ & $\begin{array}{c}-0.0071^{* * *} \\
(-2.77)\end{array}$ & $\begin{array}{c}-0.0082^{* * *} \\
(-3.26)\end{array}$ & $\begin{array}{c}-0.0068^{* * *} \\
(-2.75)\end{array}$ & $\begin{array}{l}0.059 \\
(0.41)\end{array}$ & $\begin{array}{c}-0.00755^{* * *} \\
(-4.34)\end{array}$ \\
\hline AllocPerc & & $\begin{array}{c}0.066^{* * *} \\
(4.86)\end{array}$ & $\begin{array}{c}0.064^{* * *} \\
(5.67)\end{array}$ & $\begin{array}{c}0.059^{* * *} \\
(5.23)\end{array}$ & & $\begin{array}{l}0.012 \\
(0.89)\end{array}$ \\
\hline Constant & $\begin{array}{c}0.073^{* * *} \\
(2.80)\end{array}$ & $\begin{array}{l}0.029^{*} \\
(1.74)\end{array}$ & $\begin{array}{c}0.029^{* *} \\
(2.27)\end{array}$ & $\begin{array}{l}0.072 \\
(1.39)\end{array}$ & $\begin{array}{l}1.16 \\
(0.88)\end{array}$ & $\begin{array}{l}-0.088 \\
(-1.07)\end{array}$ \\
\hline $\begin{array}{l}\text { Institution fixed effects } \\
\text { Firm fixed effects } \\
\text { Adjusted R2 } \\
\text { Observations }\end{array}$ & $\begin{array}{c}\text { No } \\
\text { No } \\
0.14 \\
8539 \\
\end{array}$ & $\begin{array}{l}\mathrm{No} \\
\mathrm{No} \\
0.15 \\
8539 \\
\end{array}$ & $\begin{array}{c}\text { Yes } \\
\mathrm{No} \\
0.24 \\
8539 \\
\end{array}$ & $\begin{array}{l}\text { Yes } \\
\text { Yes } \\
0.23 \\
8539 \\
\end{array}$ & $\begin{array}{l}\text { Yes } \\
\text { Yes } \\
0.31 \\
479 \\
\end{array}$ & $\begin{array}{l}\text { Yes } \\
\text { Yes } \\
0.17 \\
2421 \\
\end{array}$ \\
\hline
\end{tabular}




\section{Table 7}

Abnormal buying through Lead-UW versus abnormal selling through other brokers.

This table reports the estimates of OLS regressions of three dependent variables: (1)BuyLead/TotBuyi,j,t - the percentage of IPO $i$ shares bought by institution $j$ in month $t$ through the lead underwriters of the IPO $i$ in the total amount of shares bought by the same institution $j$ over month $t$; (2)SecondarySalesLead/TotSell ${ }_{i, j, t}$ - the percentage of secondary sales of IPO $i$ shares by institution $j$ in month $t$ through the lead underwriters of IPO $i$; and (3)AllocationSalesLead/TotSell ${ }_{i, j, t}$ - the percentage of allocated shares sold by institution $j$ in month $t$ through the lead underwriters of IPO $i$ from the total amount of allocated shares sold, on the variable $M o n t h 1_{t}$, which is a dummy variable equal to one in month 1 and zero in month 3 . We include the following control variables: RelVol is the number of shares traded by the institution scaled by the number of shares issued; ExcLeadComm is the average percentage commission to the lead underwriter minus the average percentage commission to any other broker paid by institutions for their buy trades (Column (1)-(2)) or sell trades (Column (3)-(4)) over a month $t$. We include institution-firm fixed effects in all specifications. All ratios are expressed in percentage terms. Standard errors are clustered at the institution level ( $t$-statistics are in parentheses). Significance levels are denoted as: ${ }^{*} 0.1,{ }^{* *} 0.05, * * * 0.01$.

\begin{tabular}{|c|c|c|c|c|c|c|}
\hline Dependent Variable: & \multicolumn{2}{|c|}{ BuyLead/TotBuy } & \multicolumn{2}{|c|}{ SecondarySalesLead/TotSell } & \multicolumn{2}{|c|}{ AllocationSalesLead/TotSell } \\
\hline Month1 & $\begin{array}{c}(1) \\
18.2^{* * *} \\
(7.21)\end{array}$ & $\begin{array}{c}(2) \\
17.3^{* * *} \\
(7.16)\end{array}$ & $\begin{array}{c}(3) \\
-5.41^{* *} \\
(-2.38)\end{array}$ & $\begin{array}{c}(4) \\
-5.30^{* *} \\
(-2.12)\end{array}$ & $\begin{array}{c}(5) \\
12.4^{* * *} \\
(7.14)\end{array}$ & $\begin{array}{c}(6) \\
11.0^{* * *} \\
(5.44)\end{array}$ \\
\hline RelVol & & $\begin{array}{l}0.70 \\
(1.33)\end{array}$ & & $\begin{array}{c}2.38^{* * *} \\
(3.92)\end{array}$ & & $\begin{array}{l}2.87^{* *} \\
(2.56)\end{array}$ \\
\hline ExcLeadComm & & $\begin{array}{l}33.6 \\
(1.55)\end{array}$ & & $\begin{array}{l}40.5 \\
(1.28)\end{array}$ & & $\begin{array}{l}76.3^{* *} \\
(2.43)\end{array}$ \\
\hline Constant & $\begin{array}{l}20.3^{* * *} \\
(12.74)\end{array}$ & $\begin{array}{l}19.6^{* * *} \\
(10.70)\end{array}$ & $\begin{array}{l}20.4^{* * *} \\
(19.40)\end{array}$ & $\begin{array}{l}18.4^{* * *} \\
(14.81)\end{array}$ & $\begin{array}{l}22.7^{* * * *} \\
(15.33)\end{array}$ & $\begin{array}{l}21.7^{* * * *} \\
(13.76)\end{array}$ \\
\hline $\begin{array}{l}\text { Inst-Firm fixed effects } \\
\text { Adjusted R2 } \\
\text { Observations }\end{array}$ & $\begin{array}{l}\text { Yes } \\
0.48 \\
6710 \\
\end{array}$ & $\begin{array}{l}\text { Yes } \\
0.48 \\
6710 \\
\end{array}$ & $\begin{array}{l}\text { Yes } \\
0.28 \\
2561 \\
\end{array}$ & $\begin{array}{l}\text { Yes } \\
0.29 \\
2561 \\
\end{array}$ & $\begin{array}{l}\text { Yes } \\
0.50 \\
9180 \\
\end{array}$ & $\begin{array}{l}\text { Yes } \\
0.51 \\
9180\end{array}$ \\
\hline
\end{tabular}


Table 8

Commissions by broker type and side of the trade.

This table reports difference of means tests for the percentage trading commission paid to lead underwriters and to any other broker by financial institutions in IPOs issued between 1999 and 2010. The sample includes 20,107 sell trades and 24,469 buy trades executed during the first month after the issue date. The percentage trading commission paid by an institution to the broker is winsorized at the $95 \%$ level. Standard errors are corrected for unequal variances (t-statistics are in parentheses). Significance levels are denoted as: * $0.1, * * 0.05, * * * 0.01$.

\begin{tabular}{cccc}
\hline \hline & All others & Lead UWs & Diff. of means \\
\hline \% sell commissions & 0.0886 & 0.0895 & -0.000869 \\
& & & $(-0.472)$ \\
$\%$ buy commissions & 0.109 & 0.122 & $-0.0124^{* * *}$ \\
& & & $(-6.814)$ \\
\hline \hline
\end{tabular}




\section{Table 9}

IV regression with distressed funds.

This table reports the estimation results of several specification of a 2SLS regression in a sample of institutional trades in 1,361 IPO stocks issued between 1999 and 2010. The dependent variable is a dummy equal to one if the broker executing the trade is any of the lead underwriters of the IPO (LeadDummy). The sample includes 44,576 trades executed in the first 21 trading days after the issue date. Panel (A) reports the first stage results; Panel (B) reports the second stage results. Column (1) reports the results of a 2SLS regression of LeadDummy on a dummy variable equal to one if the institution is selling and zero otherwise (Sell), instrumented by LnDistressFunds. LnDistressFunds is the natural logarithm of the number of funds managed by the institution that are in distress. A fund is defined to be in distress if: 1) its total volume traded in all stocks in the IPO month is more than 25 million dollars and 2) its total dollar netbuy in all stocks divided by the total volume traded is less than -0.99. Column (2) introduces several control variables: RelVol is the number of shares traded by the institution scaled by the number of shares issued; NormalTradeLead is the percentage volume of sell or buy trades in non-IPO stocks made by the institution through the lead underwriters in a 6-month period prior to the issue; Day is the day in which the trade is executed, relative to the issue date; ExcLeadComm is the average percentage commission to the lead underwriters minus the average percentage commission to any other broker paid by sample institutions for their buy or sell trades in the first 21 trading days after the issue date; AllocPerc is the percentage IPO allocation received by the institution. Columns (3) and (4) introduce institution and firm fixed effects. All non-dummy variables are winsorized at the 95\% level. Standard errors are clustered at the institution level (t-statistics are in parentheses). Significance levels are denoted as: ${ }^{*} 0.1,{ }^{* *} 0.05, * * * 0.01$.

(a) First stage

\begin{tabular}{lcccc}
\hline \hline & $(1)$ & $(2)$ & $(3)$ & $(4)$ \\
\hline LnDistressFunds & $0.11^{* * *}$ & $0.13^{* * *}$ & $0.054^{* * *}$ & $0.030^{* * *}$ \\
& $(3.17)$ & $(3.98)$ & $(8.02)$ & $(4.22)$ \\
\hline Controls & No & Yes & Yes & Yes \\
Institution fixed effects & No & No & Yes & Yes \\
Firm fixed effects & No & No & No & Yes \\
F-stat & 10.0 & 70.3 & 96.4 &. \\
Adjusted R2 & 0.0058 & 0.067 & 0.18 & 0.31 \\
Observations & 44576 & 44576 & 44576 & 44576 \\
\hline \hline
\end{tabular}

(b) Second stage

\begin{tabular}{lcccc}
\hline \hline & $(1)$ & $(2)$ & $(3)$ & $(4)$ \\
\hline Sell & $-1.32^{* * *}$ & $-1.12^{* * *}$ & $-0.56^{* * *}$ & $-1.35^{*}$ \\
& $(-3.92)$ & $(-5.26)$ & $(-3.02)$ & $(-1.65)$ \\
\hline Controls & No & Yes & Yes & Yes \\
Institution fixed effects & No & No & Yes & Yes \\
Firm fixed effects & No & No & No & Yes \\
Observations & 44576 & 44576 & 44576 & 44576 \\
\hline \hline
\end{tabular}


Table 10

Is the hiding strategy effective?

This table reports the estimates of Arellano-Bond regressions estimated with difference-GMM. The dependent variable, AvgAllocPerc, is the average percentage IPO allocation received by the institution in a 6-months period. The regressors are the average lagged 6-month trading volume components scaled by the number of shares issued: L.AvgBuyLead (L.AvgBuyNonLead) is the average relative number of shares bought through the lead underwriters (brokers other than lead underwriters); L.AvgSecondarySalesLead (L.AvgSecondarySalesNonLead) is the average relative share volume of secondary sales through lead brokers (brokers other than lead underwriters); L.AvgAllocationSalesLead (L.AvgAllocationSalesNonLead) is the relative number of allocated shares sold through lead brokers (brokers other than lead underwriters). In Column (2) we control for NormalTradeLead - the \% volume of sell or buy trades in non-IPO stocks made by the institution through the lead underwriters in a 6 -month period prior to the issues. All ratios are multiplied by 100. Columns (3) and (4) include semi-annual fixed effects. Columns (1)-(3) use one-lag instruments, Column (4) includes one-lag and two-lag instruments. Standard errors are clustered at the institution level (t-statistics are in parentheses). Significance levels are denoted as: $* 0.1, * * 0.05, * * * 0.01$.

\begin{tabular}{lcccc}
\hline Dependent Variable: & \multicolumn{4}{c}{ AvgAllocPerc } \\
\cline { 2 - 5 } & $(1)$ & $(2)$ & $(3)$ & $(4)$ \\
\hline L.AvgSecondarySalesLead & $-6.69^{* * *}$ & $-6.48^{* * *}$ & $-6.42^{* * *}$ & $-4.53^{* * *}$ \\
& $(-3.12)$ & $(-2.90)$ & $(-2.82)$ & $(-3.25)$ \\
L.AvgSecondarySalesNonLead & -0.38 & -0.44 & -0.44 & -0.24 \\
& $(-1.03)$ & $(-1.14)$ & $(-1.12)$ & $(-0.59)$ \\
L.AvgAllocationSalesLead & 0.76 & 0.68 & 0.70 & 0.84 \\
& $(1.31)$ & $(1.11)$ & $(1.12)$ & $(1.60)$ \\
L.AvgAllocationsSalesNonLead & 0.12 & 0.12 & 0.11 & -0.11 \\
& $(0.79)$ & $(0.78)$ & $(0.71)$ & $(-0.58)$ \\
L.AvgBuyLead & 0.23 & 0.21 & 0.21 & 0.13 \\
& $(1.43)$ & $(1.31)$ & $(1.32)$ & $(0.90)$ \\
L.AvgBuyNonLead & $0.35^{* *}$ & $0.34^{* *}$ & $0.34^{* *}$ & 0.14 \\
& $(2.56)$ & $(2.47)$ & $(2.44)$ & $(1.11)$ \\
L.AvgPercAlloc & 0.020 & 0.017 & 0.019 & 0.089 \\
& $(0.19)$ & $(0.16)$ & $(0.17)$ & $(0.78)$ \\
NormalTradeLead & & 0.00075 & 0.00079 & $0.00099^{* *}$ \\
& & $(1.46)$ & $(1.55)$ & $(2.31)$ \\
\hline Institution fixed effects & Yes & Yes & Yes & Yes \\
Time fixed effects & 1.9 & 1 \\
AR(2) (p-value) & 1 & 1 & 1 & 2 \\
Hansen overid. test (p-value) & 0.55 & 0.62 & 0.58 & 0.19 \\
Observations & 3696 & 3696 & 3696 & 0.079 \\
\hline \hline
\end{tabular}




\section{Appendices}

\section{A. Ancerno Data Description}

This data appendix provides a detailed description of ANcerno data inspired by years of exchanges with the data provider, as well as the explanation of the mapping procedure we use to produce the dataset. Our sample consists of institutional transaction-level trading data from ANcerno/Abel Noser Solutions. ANcerno clients (money managers, pension plan sponsors, and brokers) provide their trading data to ANcerno to monitor their transaction costs. Each client has a unique numerical identifier in the dataset (clientcode) that allows distinguishing among the three types of clients. Nevertheless, the identity of the client is anonymized. We use clientcode mainly as a technical variable in several matching exercises we perform. One of the main variables of interest to us is managercode by ANcerno attributed to the trading institutions. After receiving data from their clients, ANcerno assigns a code to each manager within the client's portfolio. Because several clients may use the same manager, in order to associate a manager with a particular client, ANcerno codes the manager in relation to a client. Another reason they do this is because different clients may report the same managers differently (e.g., different spelling). By coding the manager in relation to a customer, ANcerno can trace back the manager to a particular client. Managers can be grouped across clients by using the managercode. ANcerno uses the same logic in mapping executing brokers in the data. The main ANcerno trading dataset includes clientcode, clientmgrcode and clientbkrcode we use in our matching process.

ANcerno data is subscription specific. For a limited period of time in 2010, ANcerno provided its academic subscribers with the identification table "MasterManagerXref" that includes managercodes with the associated names of trading institutions. The file 
we got includes 1088 unique institutions. Additional identification files "ManagerXref" and "BrokerXref" include clientcode, clientmgrcode, and clientbkrcode variables allowing to link fund families and brokers to the trading data in the main ANcerno dataset. The mapping procedure we use is shown in detail in Figure A1. Figure A1 shows the twostep matching we use to get the managing company name on the main ANcerno trading dataset. In the first step, we merge "ManagerXref" file on the main ANcerno table using clientcode-clientmgrcode as a key identifier. We further link the resulting table with the managing company name (variable manager) from the "MasterManagerXref" file on provided (managercodes).

We use the S12type5 Table provided by Wharton Research Data Services (WRDS) to map management companies from SEC $13 \mathrm{~F}$ filings to mutual funds reporting their holdings in the Thomson Reuters S12 Mutual fund holdings database. S12 data contains funds associated to fund families in 13F. Finally, we match ANcerno institutions with the institutions from S12/13F Thomson Reuters database. We manually match managing company names from both datasets: variable manager in ANcerno and mgrco in S12 database. 


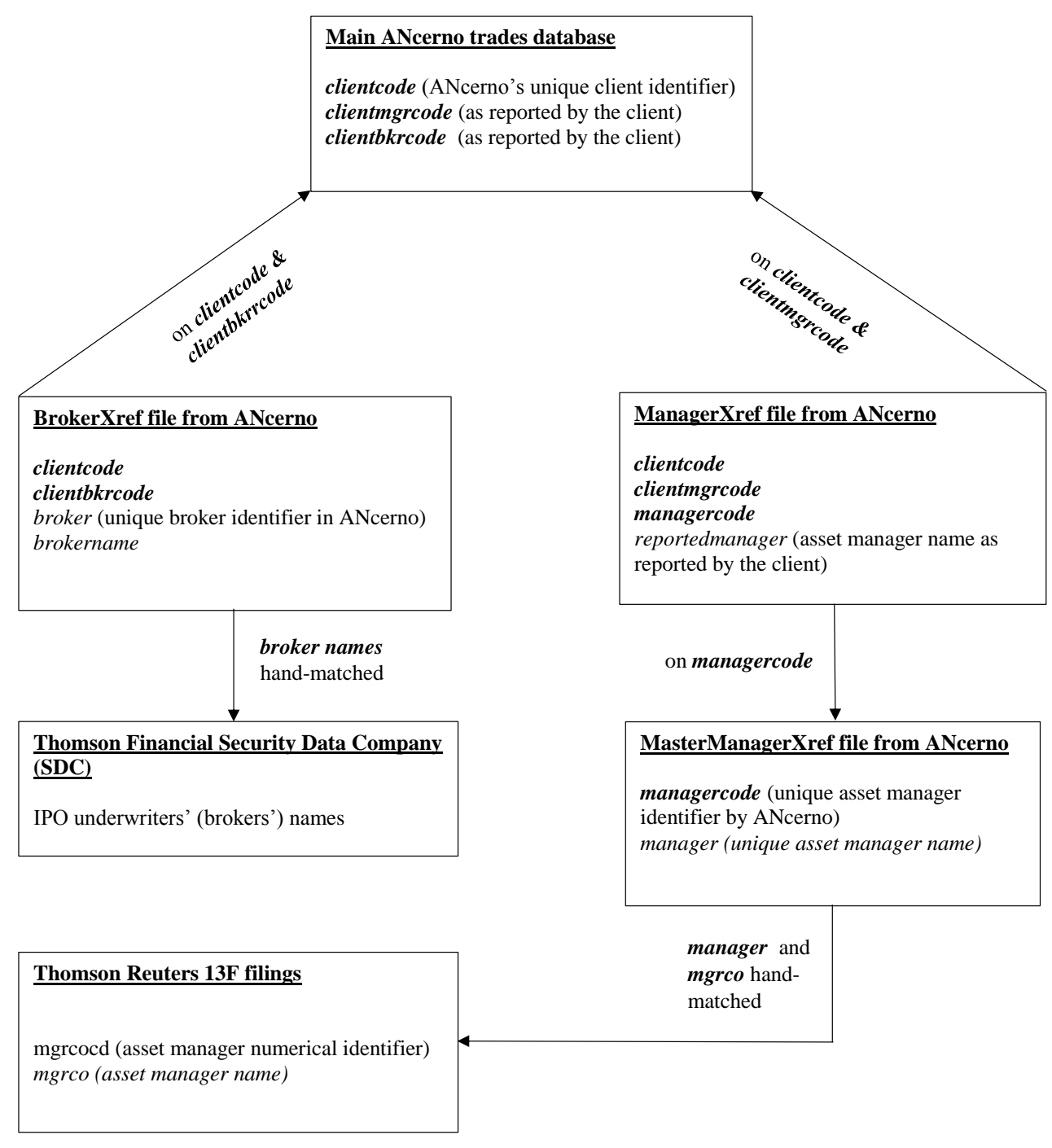

Fig. A1. Mapping money managers and brokers across databases (key identifier(s) for the match are provided in bold). 


\section{B. Allocation Sales}

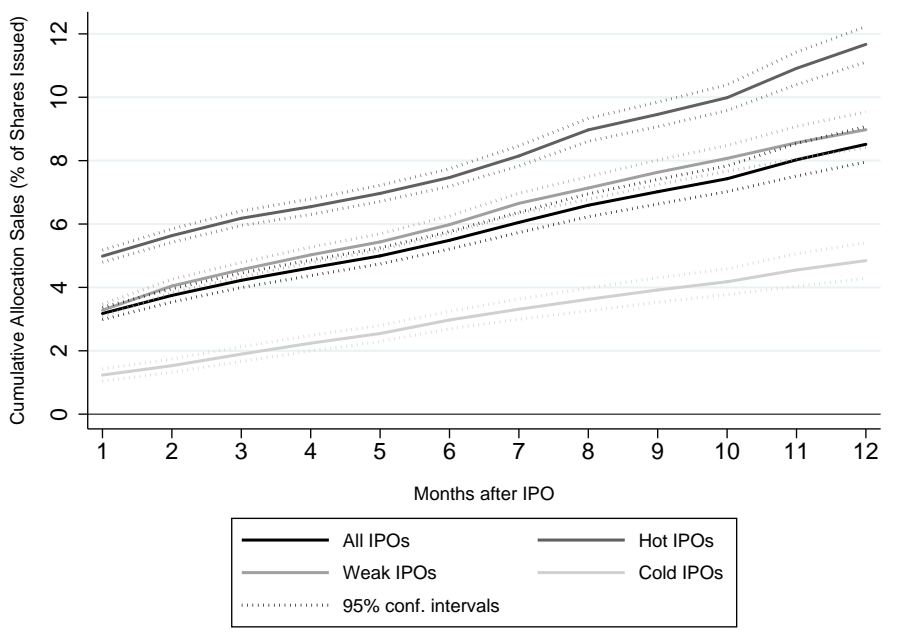

Fig. B2. Allocation sales by IPO type. This figure plots the average cumulative percentage of allocated IPO shares sold, scaled by the number of shares offered, by month from the issue date. $95 \%$ confidence intervals are reported with dotted lines. The black line report the average for the whole sample of IPOs. The grey lines break the averages down for hot IPOs (highest tercile of Underpricing), weak IPOs (middle tercile of Underpricing), and cold IPOs (lowest tercile of Underpricing). 


\section{Further Robustness Tests}

We use a linear probability model (LPM) in our baseline regressions and we estimate its coefficients via OLS. We justify the use of OLS because the unconditional probability of trading with the lead underwriters is not at the boundaries of the unit interval (it is 0.292). Moreover, a very small proportion of the predicted probabilities of trading with the lead underwriters fall outside the $[0,1]$ interval and only one specification out of five suffers of this problem (see Table 3). Horrace and Oaxaca (2006) show that OLS is unbiased and consistent if all the observations have true predicted probabilities within the unit interval. We cannot know the true predicted probabilities, but our predicted probabilites do not raise suspect that potential OLS biasedness and inconsistency are relevant concerns in our setting. Finally, a LPM is desirable in our situation because it allows us to control for fixed effects without incurring in the incidental parameter problem and it estimates marginal effects. For robustness, we also run logit regressions and get rid of the fixed effects by means of a conditional logit model. Table C1 reports the estimation results, which are overall consistent with our baseline regressions. ${ }^{25}$

Almost $50 \%$ of the IPOs in our sample are issued during the internet bubble period. We replicate our regression analysis excluding IPOs issued in 1999 and 2000 and report our findings in Table C2. The results are similar to those of our baseline regressions. We use LeadDummy as dependent variable in our baseline regressions. This implies that we pool in the same group of brokers the other syndicate members and brokers that do not belong to the underwriting syndicate. For robustness, we replicate our regression analysis using $U W D$ Dmmy as dependent variable. UWDummy takes the

\footnotetext{
${ }^{25}$ We cannot estimate all the specifications because of computational problems with the conditional logit model. In unreported analyses, we also run the LPM while trimming observations with predicted probabilities outside the unit interval, as suggested by Horrace and Oaxaca (2006). If anything, our results get stronger.
} 
value of 1 if the trade is executed through any of the underwriters of the IPO and zero otherwise. Table $\mathrm{C} 3$ shows that results are overall consistent with our baseline regressions. If anything, they are slightly weaker, consistent with hiding incentives being mainly related to lead underwriters. 


\section{Table C1}

Buy-Sell asymmetry: logit and conditional logit specifications.

This table reports the coefficient estimates of logit and conditional logit models in a sample of institutional trades in 1,361 IPO stocks issued between 1999 and 2010. The dependent variable is a dummy equal to one if the broker executing the trade is any of the lead underwriters of the IPO (LeadDummy). The original sample includes 44,576 trades executed in the first 21 trading days after the issue date. Column (1) reports the results of a logit regression of LeadDummy on a dummy variable equal to one if the institution is selling and zero otherwise $(\mathrm{Sell})$. Column (2) introduces several control variables: RelVol is the number of shares traded by the institution scaled by the number of shares issued; NormalTradeLead is the percentage volume of sell or buy trades in non-IPO stocks made by the institution through the lead underwriters in a 6 -month period prior to the issue; Day is the day in which the trade is executed, relative to the issue date; ExcLeadComm is the average percentage commission to the lead underwriters minus the average percentage commission to other brokers paid by sample institutions for their buy or sell trades in the first 21 trading days after the issue date; AllocPerc is the percentage IPO allocation received by the institution. Column (3) controls for institution-firm fixed effects by means of a conditional logit model. All non-dummy variables are winsorized at the $95 \%$ level. Standard errors are clustered at the institution level (t-statistics are in parentheses). Significance levels are denoted as: $* 0.1, * * 0.05, * * * 0.01$.

\begin{tabular}{lccc}
\hline Dependent Variable: & \multicolumn{3}{c}{ LeadDummy } \\
\cline { 2 - 4 } & $(1)$ & $(2)$ & $(3)$ \\
\hline Sell & $-0.29^{* *}$ & $-0.40^{* * *}$ & $-0.37^{* *}$ \\
& $(-2.07)$ & $(-3.64)$ & $(-2.44)$ \\
RelVol & & $0.31^{* *}$ & $1.04^{* * *}$ \\
& & $(2.57)$ & $(7.60)$ \\
NormalTradeLead & & $0.041^{* * *}$ & 0.019 \\
& & $(4.92)$ & $(0.78)$ \\
Day & & $-0.059^{* * *}$ & $-0.069^{* * *}$ \\
& & $(-6.09)$ & $(-5.07)$ \\
ExcLeadComm & & -0.87 & $-1.56^{*}$ \\
& & $(-1.15)$ & $(-1.79)$ \\
AllocPerc & & -0.0011 & \\
& & $(-0.05)$ & \\
Constant & & \\
& & & \\
Institution-Firm fixed effects & No & $(-4.08)$ \\
Pseudo R2 & 0.0036 & 0.041 & Yes \\
Observations & 44576 & 44576 & 21693 \\
\hline \hline
\end{tabular}




\section{Table C2}

Dropping 1999-2000 period.

This table reports the estimation results of several specification of a linear probability model in a sample of institutional trades in 698 IPO stocks issued between 2001 and 2010. The dependent variable is a dummy equal to one if the broker executing the trade is any of the lead underwriters of the IPO (LeadDummy). The sample includes 24,109 trades executed in the first 21 trading days after the issue date. Column (1) reports the results of an OLS regression of LeadDummy on a dummy variable equal to one if the institution is selling and zero otherwise $(\mathrm{Sell})$. Column (2) introduces several control variables: RelVol is the number of shares traded by the institution scaled by the number of shares issued; NormalTradeLead is the percentage volume of sell or buy trades in non-IPO stocks made by the institution through the lead underwriters in a 6 -month period prior to the issue; Day is the day in which the trade is executed, relative to the issue date; ExcLeadComm is the average percentage commission to the lead underwriters minus the average percentage commission to other brokers paid by sample institutions for their buy or sell trades in the first 21 trading days after the issue date; AllocPerc is the percentage IPO allocation received by the institution. Columns (3), (4), and (5) introduce institution, firm, and institution-firm fixed effects. All non-dummy variables are winsorized at the $95 \%$ level. Standard errors are clustered at the institution level (t-statistics are in parentheses). Significance levels are denoted as: ${ }^{*} 0.1$, ** $0.05,{ }^{* * *} 0.01$.

\begin{tabular}{lccccc}
\hline \hline Dependent Variable: & \multicolumn{5}{c}{ LeadDummy } \\
\cline { 2 - 6 } & $(1)$ & $(2)$ & $(3)$ & $(4)$ & $(5)$ \\
\hline Sell & $-0.052^{* *}$ & $-0.067^{* * *}$ & $-0.060^{* * *}$ & $-0.055^{* * *}$ & $-0.050^{* *}$ \\
& $(-2.27)$ & $(-3.48)$ & $(-3.78)$ & $(-3.43)$ & $(-2.34)$ \\
\hline Controls & No & Yes & Yes & Yes & Yes \\
Institution fixed effects & No & No & Yes & Yes & No \\
Firm fixed effects & No & No & No & Yes & No \\
Institution-Firm fixed effects & No & No & No & No & Yes \\
Adjusted R2 & 0.0032 & 0.063 & 0.15 & 0.24 & 0.40 \\
Observations & 24109 & 24109 & 24109 & 24109 & 24109 \\
\% Outside [0,1] & 0 & 0.0016 & 0.00040 & 0.072 & 0 \\
\hline \hline
\end{tabular}




\section{Table C3}

Including all underwriter syndicate members.

This table reports the estimation results of several specification of a linear probability model in a sample of institutional trades in 1361 IPO stocks issued between 1999 and 2010. The dependent variable is a dummy equal to one if the broker executing the trade is any of the underwriters of the IPO (UWDummy). The sample includes 44,576 trades executed in the first 21 trading days after the issue date. Column (1) reports the results of an OLS regression of UW Dummy on a dummy variable equal to one if the institution is selling and zero otherwise $(\mathrm{Sell})$. Column (2) introduces several control variables: RelVol is the number of shares traded by the institution scaled by the number of shares issued; NormalTradeUW is the percentage volume of sell or buy trades in non-IPO stocks made by the institution through the underwriters in a 6-month period prior to the issue; Day is the day in which the trade is executed, relative to the issue date; ExcUWComm is the average percentage commission to the underwriters minus the average percentage commission to other brokers paid by sample institutions for their buy or sell trades in the first 21 trading days after the issue date; AllocPerc is the percentage IPO allocation received by the institution. Columns (3), (4), and (5) introduce institution, firm, and institution-firm fixed effects. All non-dummy variables are winsorized at the $95 \%$ level. Standard errors are clustered at the institution level (t-statistics are in parentheses). Significance levels are denoted as: ${ }^{*} 0.1$, ** $0.05,{ }^{* * *} 0.01$.

\begin{tabular}{lccccc}
\hline Dependent Variable: & \multicolumn{5}{c}{ UWDummy } \\
\cline { 2 - 6 } & $(1)$ & $(2)$ & $(3)$ & $(4)$ & $(5)$ \\
\hline Sell & $-0.066^{* *}$ & $-0.080^{* * *}$ & $-0.051^{* * *}$ & $-0.049^{* *}$ & $-0.044^{*}$ \\
& $(-2.07)$ & $(-3.33)$ & $(-2.90)$ & $(-2.59)$ & $(-1.85)$ \\
\hline Controls & No & Yes & Yes & Yes & Yes \\
Institution fixed effects & No & No & Yes & Yes & No \\
Firm fixed effects & No & No & No & Yes & No \\
Institution-Firm fixed effects & No & No & No & No & Yes \\
Adjusted R2 & 0.0047 & 0.053 & 0.14 & 0.25 & 0.42 \\
Observations & 44576 & 44576 & 44576 & 44576 & 44576 \\
\% Outside [0,1] & 0 & 0 & 0 & 0.042 & 0 \\
\hline \hline
\end{tabular}

